\title{
Decentralized Robust Control of Robot Manipulators with Harmonic Drive Transmission and Application to Modular and Reconfigurable Serial Arms
}

\begin{abstract}
In this paper, we propose a decentralized robust control algorithm for modular and reconfigurable robots (MRRs) based on Lyapunov's stability analysis and backstepping techniques. In using decentralized control schemes with robot manipulators, each joint is considered as an independent subsystem, and the dynamical effects from the other links and joints are treated as disturbance. However, there exist many uncertainties due to unmodeled dynamics, varying payloads, harmonic drive (HD) compliance, HD complex gear meshing mechanisms, etc. Also, while the reconfigurability of MRRs is advantageous, modifying the configuration will result in changes to the robot dynamics parameters, thereby making it challenging to tune the control system. All the above mentioned disturbances in addition to reconfigurability present a challenge in controlling MRRs. The proposed controller is well-suited for MRR applications because of its simple structure that does not require the exact knowledge of the dynamic parameters of the configurations. Desired tracking performance can be achieved via tuning a limited set of parameters of the robust controller. If the numbers of degrees of freedom are held constant, these parameters are shown to be relatively independent of the configuration, and can be held constant between changes in configuration. This strategy is novel compared to existing MRR control methods. In order to validate the controller performance, experimental setup and results are also presented.
\end{abstract}

\section{Index Terms}

Modular and Reconfigurable Robot, robust, decentralized, Lyapunov, backstepping.

Z. Li and W. W. Melek: University of Waterloo, 200 University Avenue West, Waterloo, Ontario, Canada N2L 3G1

Email: z371i@engmail.uwaterloo.ca ; wmelek@mecheng1.uwaterloo.ca

C. Clark: California Polytechnic State University, San Luis Obispo, CA 93407

Email: cmclark@,calpoly.edu 


\section{INTRODUCTION}

Robot manipulators have served the manufacturing industry for many years. But due to the fast growth of the economy, the conventional fixed-anatomy robots will not satisfy the requirements of a transition from mass to customer-oriented production. To respond to rapid changes of product design, manufacturers need a more flexible fabrication system. A commonly used method is to use programmable robots that are expensive, and limited by hardware constraints. In recent years, modular and reconfigurable robots (MRRs) [1][2] were proposed to fulfill the requirements for the flexible production system. The majority of the associated research is geared towards self-reconfigurable robots [3][4]. At present, the application of reconfigurable robots in manufacturing is quite limited. However recent technology and research advances are very promising. As an extension of the concept of a modular robot system, the MRR system is referred to the entire manipulator system that includes not only the modular mechanical hardware, but also modular electrical hardware, control algorithms and software [2]. In [5], an MRR system is defined as a collection of individual link and joint components that can be easily assembled into a variety of configurations and different geometries. In [6], the author states that in the near future the MRR system will mostly replace current fixed configuration industrial robots.

Except for reconfigurability requirements, lighter manipulators that can handle heavier payloads have brought more attention to both robot designers and industrial manufacturers. To achieve this, harmonic drives (HD) have been widely used in robotic system design due to its compact size, zero back-lash, light weight, high torque transmission [1][2][7]. Unfortunately they exhibit drawbacks including the flexspline elasticity, and complex meshing mechanisms between the flexspline and circular spline. 
MRRs with HDs have more uncertainties in the mechanical system. Therefore, to control such a system is more challenging. The selection of the control law not only depends on the robot mechanical design, i.e. rotary joint robot and Cartesian manipulator, but also relies on the model used. Based on the assumption made on the manipulator's joints, links, and the control signal, six manipulator models are commonly encountered in the literature: 1) torque level rigid link rigid joint (TLRLRJ) [8][9][10]; 2) electrically driven rigid link rigid joint (EDRLRJ) [11]; 3) torque level rigid link flexible joint (TLRLFJ) [12][13][14]; 4) electrically driven rigid link flexible joint (EDRLFJ) [15]; and 5) flexible manipulator (FM) [16]. A considerable number of control techniques and methodologies have been created and applied to the control of manipulators. In this paper, the controller development for MRR systems is based on TLRLFJ.

Joint flexibility is a major source of oscillatory behaviour of the manipulator, and considerably affects a robot's performance. A widely acceptable TLRLFJ model was introduced in [17], where the robot was modeled as two second order differential equations under the assumption of 1) the joints are purely rotary; and 2) the rotor/gear inertia is symmetric about the rotation axis. This dynamic model was shown to be globally linearizable and a nonlinear control was provided based on a singular perturbation formulation of the equations of motion and the concept of integral manifold, but the author did not prove the stability of the system. Based on the same theories, a composite control algorithm with detailed stability analysis was proposed in [14], which consists of a fast control and a slow control. In [18], a fuzzy supervisor was added to decrease the fast controller bandwidth at critical occasions, i.e. near saturation point which could cause instable.

Robust control is a commonly used strategy to control complex systems, especially for robot manipulators. [19] presents a summary of robust control method before 1997 in the categories of linear, passivity-based, Lyapunov-based, sliding mode, nonlinear and robust adaptive control schemes. [20] provides detailed design procedure of centralized Lyapunov-based robust control for an n-dof manipulator under joint flexibility. [21] standardizes some robust controller, such as saturation type controller, passivity 
controller, etc. For decoupled joint controller, each joint is considered as a single input single output (SISO) subsystem. A general form of decentralized sliding mode robust control law is proposed in [23] for any mechanical system described by Euler-Lagrange equation and involving high-order interconnections. In [24], another simple decentralized nonlinear control algorithm was developed. This controller had three integral terms in the tracking error, and a systematic method for controller parameters selection is also provided. But those controllers [23][24] were designed for TLRLRJ. In [22] a linear PD/PID compensator has been designed by considering actuator saturation and transmission flexibility. Other controllers, such as PD/PID with gravitational compensation, intelligent fuzzy controller, etc., can be found in [25][26][27][28][29].

To the best of our knowledge, there exists very limited research dedicated to control of MRRs. This is most likely because a new configuration of the robot results in a new set of robot dynamic parameters. In [30], an MRR control approach is proposed that focuses on the "high-level" analysis of the feasibility of a decentralized strategy that handles serial arms as a group of 1 DOF defective joints. Unlike the approach in [30], this paper presents a decentralized robust controller for MRRs with HD that uses Lyapunov-based method and backstepping techniques. Furthermore, unlike the control software presented in [31] which requires configuration dependent parameters, our proposed controller is configuration independent. Therefore, the proposed controller will enable fast reconfigurability of the manipulator as well the control strategy to achieve precise position tracking in the task space of the manipulator.

The organization of the paper is follows: Section II introduces the dynamic model. Section III describes the controller design. Section IV provides the experiments setup and results. The conclusions are documented in Section V.

\section{MRR SINGLE JOINT MODEL}

A commonly used model for an n-dof of torque level rigid link flexible joint (TLRLFJ) model is introduced in [17] in the form of:

$$
\left.D\left(q_{1}\right) \dot{q}_{1}+C\left(q_{1}, \dot{q}_{1}\right)+k\left(q_{1}-q_{2}\right)=\right)
$$




$$
J \ddot{q}_{2}-:\left(q_{1}-!_{2}\right)=\iota
$$

Where, $D\left(q_{1}\right)$ is a $n \times$ symmetric, positive definite inertial matrix. The vector $C\left(q_{1}, \dot{q}_{1}\right)$ contains coriolis, centripetal, friction and gravitational forces and torques. $k$ and $J$ are the $n \times$ : diagonal stiffness coefficients and motor inertial matrix, respectively. For the development of the decentralized control scheme, most papers [12][25] are based on the above two equations and consider the inertial coupling term, the Coriolis, centrifugal, friction and gravity terms in (1) as a disturbance torque. In this paper, a decentralized controller is designed based on single joint dynamics including friction, gravity and compliance.

A single joint with harmonic drive (HD) can be modeled as a mass-spring system with three subsystems: 1) motor and wave generator (input) subsystem; 2) flexspline (transmission) subsystem; 3) link and load (output) subsystem.

By applying Euler-Lagrange theorem, three equations can be derived for each subsystem (see Appendix):

$$
\begin{array}{r}
\dot{J}_{m w} \ddot{q}_{2}+F_{m d} \dot{q}_{2}+F_{m s} \operatorname{sign}\left(\dot{q}_{2}\right)+N \tau_{f}= \\
K_{s 1}\left(N q_{2}-{ }_{1}\right)+Y_{s 2}\left(N q_{2}-{ }_{1}\right)^{3}= \\
\left.\dot{J}_{l} \ddot{q}_{1}+m g l \operatorname{sign}\left(\dot{q}_{1}\right)+F_{l d} \dot{q}_{1}+F_{l s} \operatorname{sign}\left(\dot{q}_{1}\right)\right)+\tau-\tau_{v}=
\end{array}
$$

In this model, the HD flexspline compliance is modeled as a nonlinear cubic function [32][33] as shown in (4). Substituting (4) into (3) and (5) yields two equations representing the single joint dynamics:

$$
\begin{aligned}
& \tau=I_{m w} \dot{q}_{2}+{ }_{m d} \dot{q}_{2}+{ }_{m s} \operatorname{sign}\left(\dot{q}_{2}\right)+\mathrm{V} K_{s 1}\left(N q_{2}-r_{1}+\mathrm{V} K_{s 2}\left(N q_{2}-l_{1}\right)^{3}\right. \\
& 0=I_{l} \dot{q}_{1}+n g l \sin \left(q_{1}\right)+{ }_{l d} \dot{q}_{1}+{ }_{l s} \operatorname{sign}\left(\dot{q}_{1}\right)-\zeta_{s 1}\left(N q_{2}-l_{1}\right)-\zeta_{s 2}\left(N q_{2}-r_{1}\right)^{3}+\cdot
\end{aligned}
$$

Notations used in (6) and (7) are:

$J_{m w}$ - motor rotor and HD wave-generator inertial

$F_{m d}, F_{m s}$ - input dynamic and static friction coefficients 
$K_{s 1}, K_{s 2}$ - flexspline stiffness coefficients

$q_{2}, \dot{q}_{2}, \dot{q}_{2}$ - motor position, velocity and acceleration

$N$ - HD gear reduction ratio

$\tau$ - motor input torque

$J_{l}$ - output side inertia (link, load)

$m$ - link mass

$l$ - link length

$F_{l d}, F_{l s}$ - output side dynamic and static friction coefficients

$q_{1}, \dot{q}_{1}, \ddot{q}_{1}-$ link position, velocity and acceleration

$\tau$ - disturbance torque

\section{CONTROLLER DESIGN}

We can use two cascaded subsystems representing motor dynamics (6) and robot dynamics (7), respectively, as shown in Fig. 1. The first subsystem of motor dynamics has the input $\tau$, the motor control torque, and outputs, $q_{2}, \dot{q}_{2}$ and $\dot{q}_{2}$, the motor states. The motor position $q_{2}$ is considered as the input to the second subsystem of robot dynamics which outputs $q_{1}, \dot{q}_{1}$ and $\ddot{q}_{1}$, the link states. The robot control signal $q_{2}$ is not the control signal that is sent to the system. In this situation, the backstepping [34] method is to be used, and the robot input signal $q_{2}$ is called the fictitious control signal [20]. The motor or system input signal $\tau$ is called the system control signal. In order to design the system control signal $\tau$, the fictitious control signal needs to be selected first, then stepped back to the system control signal. Both fictitious control and system control signal are designed based on the Lyapunov direct method. The proposed control law consists two terms: 1) a linear PD control, and 2) a nonlinear term to compensate for disturbances to the system.

To develop the controller, we introduce the following preliminary definitions [20] made on parameters in equations (6) and (7). 
Inertia: $0<I<\tilde{I}$

Friction: $\left\|F_{s}(\dot{q})+F_{d} \dot{q}\right\| \leq F_{1}+F_{2}\|\dot{q}\|$

Flexibility: $0<\zeta_{i}<\tilde{\zeta}_{i}$

Disturbance: $0<\tau_{\text {. }}<$.

Where $\tilde{J}$ and $\tilde{K}_{i}$ present the largest motor/link inertia and the largest stiffness coefficients of the MRR, respectively and $\tilde{\tau}$ is the maximum disturbance.

\section{A. Fictitious Control Law Selection}

Suppose that the manipulator joint is required to track a desired joint angle $q_{1}^{d}$ which has at least third order differentiability so that the desired velocity $\dot{q}_{1}^{t}$ and desired acceleration $\ddot{q}_{1}^{d}$ exist and can be derived from the derivative of $q_{1}^{d}$. The link error dynamics are calculated by adding $J_{l} \dot{q}_{1}{ }^{d}$ on both sides of (7), and after some manipulation, the link error dynamics can be formed as:

$\left.\ddot{e}_{1}=\ddot{l}_{1}{ }^{d}+J_{1}\right)^{-}\left[F_{l d} \dot{q}_{1}+F_{l s} \operatorname{sign}\left(\dot{q}_{1}\right)+n g l \sin \left(q_{1}\right)+\zeta_{s 1} q_{1}-\zeta_{s 2}\left(N q_{2}-r_{1}\right)^{3}+\tau-\zeta_{s 1} N q_{2}\right]$

Let

$f\left(\dot{q}_{1}, q_{1}, q_{2}\right)={ }_{l d} \dot{q}_{1}+{ }_{l s} \operatorname{sign}\left(\dot{q}_{1}\right)+n g l \sin \left(q_{1}\right)+\zeta_{s 1} q_{1}-\zeta_{s 2}\left(N q_{2}-l_{1}\right)^{3}+\cdot$

So equation (12) can be simplified as:

$$
\left.\ddot{e}_{1}=\ddot{l}_{1}{ }^{d}+J_{1}\right)^{-}\left[f\left(\dot{q}_{1}, q_{1}, q_{2}\right)-\zeta_{s 1} N q_{2}\right]
$$

The function $f\left(\dot{q}_{1}, q_{1}, q_{2}\right)$ includes all the uncertainties of the link dynamics, i.e. friction, stiffness and load disturbance. Based on assumptions made in equation (9)-(11), the bounded uncertainty can be calculated: 


$$
\begin{aligned}
& f\left(\dot{q}_{1}, q_{1}, q_{2}\right)={ }_{{ }_{l s}} \operatorname{sign}\left(\dot{q}_{1}\right)+\eta g l \sin \left(q_{1}\right)+\tau+\Gamma_{s 1} q_{1}+\vec{r}_{l d} \dot{q}_{1}-\zeta_{s 2}\left(N q_{2}-\prime_{1}\right)^{3} \\
& \leq \bar{r}_{l s}+\eta g l+\tau+r_{s 1} q_{1}+\vec{r}_{l d} \dot{q}_{1}-r_{s 2}\left(N q_{2}-{ }_{1}\right)^{3} \\
& =r_{10}+r_{11} q_{1}+r_{12} \dot{q}_{1}-r_{13}\left(N q_{2}-i_{1}\right)^{3} \\
& \equiv 1 \\
& \left\|\Delta f \mid \leq K_{10}+K_{11}\right\| q_{1}\left\|+K_{12}\right\| \dot{q}_{1}\left\|+K_{13}\right\|\left(N q_{2}-q_{1}\right)^{3} \| \equiv,
\end{aligned}
$$

The fictitious control signal $q_{2}$ in (14) can be chosen in the following form [20]:

$$
q_{2}=\frac{J_{l}}{K_{s 1} N}\left(\ddot{q}_{1}^{d}+\zeta_{1} e_{1}+\check{\Sigma}_{2} \dot{e}_{1}\right)+\frac{1}{K_{s 1} N} u_{r}
$$

Where $K_{s 1} \neq 1, K_{1}>1$ and $K_{2}>1$ are linear PD control gains, and $u_{r}$ is an additional term designed to compensate the nonlinear uncertainties. Substitute (17) into (14), and the closed loop link error dynamics are:

$$
\left.\ddot{e_{1}}=-r_{1} e_{1}-\zeta_{2} \dot{e}_{1}+J_{1}\right)^{-}\left(f\left(\dot{q}_{1}, q_{1}, q_{2}\right)-\iota_{r}\right)
$$

To find the nonlinear term $u_{r}$, the following Lyapunov function candidate is considered [20]:

$$
\dot{V}_{1}^{\prime}=\frac{1}{2} K_{1} e_{1}^{2}+\frac{1}{2} \dot{e}_{1}^{2}
$$

Clearly, it is positive definite, and $K_{1}$ is the same PD control gain as shown in (17). Take the derivative on both sides and substitute (18) into it, we can have:

$$
\begin{aligned}
\dot{V}_{1}^{\prime} & =\zeta_{1} e_{1} \dot{e}_{1}+\dot{ }_{1} \dot{e}_{1} \\
& \left.=\zeta_{1} e_{1} \dot{e}_{1}+\dot{i}_{1}\left(-r_{1} e_{1}-r_{2} \dot{e}_{1}+J_{1}\right)^{-}\left(f-r_{r}\right)\right) \\
& \left.=-r_{2}\left\|\dot{e}_{1}\right\|^{2}+J_{1}\right)^{-} \dot{e}_{1}\left(f-r_{r}\right) \\
& \left.\leq-r_{2}\left\|\dot{e_{1}}\right\|^{2}+J_{1}\right)^{-} \dot{e}_{1}\left(\Delta-r_{r}\right)
\end{aligned}
$$

If we select $u_{r}=1$, then $\dot{V}_{1}^{\prime} \leq 1$ is guaranteed. Therefore, the fictitious control law is: 


$$
\left.\left.q_{2}=\frac{J_{l}}{K_{s 1} N} \dot{q_{1}}{ }^{d}+K_{1} e_{1}+K_{2} \dot{e_{1}}\right)+\frac{1}{K_{s 1} N} \Delta f \equiv\right\}
$$

Equation (21) represents the fictitious control law, which is a saturation type control [21] because the nonlinear term $\Delta$ is bounded.

\section{B. Backstepping}

The fictitious control law has been selected, but it needs to be backstepped to the side of

the motor dynamics subsystem. To do so, we can add and subtract $\left(J_{l}\right)^{-} K_{s 1} N \phi$ to the right side of (14), where $\phi$ denotes the fictitious control variable:

$$
\left.\ddot{e_{1}}=\ddot{q}_{1}^{d}+J_{1}\right)^{-}\left(f-K_{s 1} N \phi-J_{1}\right)^{-} K_{s 1} N\left(q_{2}-\right.\text { \} }
$$

Equations (22) and (6) form the new dynamics of the single joint. If $q_{2}-\phi=1$, then equation (22) is stable since $\phi$ is a robust controller, as shown above. Therefore, our goal is to design robust control law $\tau$ in equation (6) such that $q_{2}-;$ either converges to zero or at least is bounded by a small constant. The following Lyapunov candidate for the overall system is used [20]:

$$
\begin{aligned}
V & =V_{1}+V_{2}+V_{3} \\
& \left.\left.=\frac{1}{2} K_{1} e_{1}^{2}+\frac{1}{2}\left(\dot{e}_{1}\right)^{2}\right]+\frac{1}{2} K_{3} e_{2}^{2}+\frac{1}{2}\left(\dot{e}_{2}\right)^{2}\right]+\frac{1}{2}\left(q_{2}-i^{2}\right.
\end{aligned}
$$

Where, $K_{3}>1$ is another PD controller gain which will be defined later. Replacing $\dot{e}_{1}$ by new error dynamics (22) and substituting the fictitious control $\phi$ yields: 


$$
\begin{aligned}
\dot{V}_{1}= & K_{1} e_{1} \dot{e}_{1}+\dot{e}_{1} \dot{e}_{1} \\
= & K_{1} e_{1} \dot{e}_{1}+\dot{e}_{1}\left(\dot{q}_{1}^{d}+J_{l}\right)^{-}\left[f-K_{s 1} N \phi-J_{l}\right)^{-} K_{s 1} N\left(q_{2}-i\right) \\
= & \left.\left.\left.K_{1} e_{1} \dot{e}_{1}+\dot{e}_{1} \dot{q}_{1}^{d}+J_{1}\right)^{-}\left[f-K_{s 1} N\left(\frac{J_{l}}{K_{s 1} N} \dot{q}_{1}^{d}+K_{1} e_{1}+K_{2} \dot{e}_{1}\right)+\frac{1}{K_{s 1} N} \Delta f\right)\right]\right\} \\
& \left.-J_{l}\right)^{-} K_{s 1} N \dot{e}_{1}\left(q_{2}-i\right. \\
= & \left.\left.K_{1} \dot{e}_{1} \dot{e}_{1}+\dot{e}_{1}\left(-K_{1} e_{1}-K_{2} \dot{e}_{1}\right)+J_{l}\right)^{-} \dot{e}_{1}(f-s f)-J_{l}\right)^{-} K_{s 1} N \dot{e}_{1}\left(q_{2}-;\right. \\
\leq & \left.-K_{2}\left\|\dot{e_{1}}\right\|^{2}-J_{l}\right)^{-} K_{s 1} N \dot{e}_{1}\left(q_{2}-;\right.
\end{aligned}
$$

In order to calculate the derivative of $V_{2}$, the motor error dynamics need to be formed.

Add $J_{m w} \ddot{q}_{2}$ to both sides of (6) and perform some simple manipulation, we have:

$$
\begin{gathered}
J_{m w}\left(\dot{q}_{2}^{d}-\dot{q}_{2}\right)=J_{m w} \dot{q}_{2}+F_{m d} \dot{q}_{2}+F_{m s} \operatorname{sign}\left(\dot{q}_{2}\right)+N K_{s 1}\left(N q_{2}-q_{1}\right)+N K_{s 2}\left(N q_{2}-q_{1}\right)^{3}- \\
\ddot{e}_{2}=\dot{q}_{2}+J_{m w}^{-}\left[g\left(\dot{q}_{2}, q_{2}, q_{1}\right)-\right.
\end{gathered}
$$

Similar to $f\left(\dot{q}_{1}, q_{1}, q_{2}\right)$ in (16), $g\left(\dot{q}_{2}, q_{2}, q_{1}\right)$ contains all the uncertainties of the motor dynamic subsystem, i.e. motor rotor friction, flexspline compliance, and the upper bounded function is defined as:

$$
\begin{gathered}
g\left(\dot{q}_{2}, q_{2}, q_{1}\right)={ }_{m d} \dot{q}_{2}+\overrightarrow{7}_{m s} \operatorname{sign}\left(\dot{q}_{2}\right)+V K_{s 1}\left(N q_{2}-r_{1}\right)+V K_{s 2}\left(N q_{2}-l_{1}\right)^{3} \\
\left\|g\left(\dot{q}_{2}, q_{2}, q_{1}\right)\right\| \leq K_{20}+K_{21}\left\|\dot{q}_{2}\right\|+K_{22}\left\|\left(N q_{2}-q_{1}\right)\right\|+K_{23}\left\|\left(N q_{2}-q_{1}\right)^{3}\right\| \\
\equiv 3
\end{gathered}
$$

Similar to the fictitious control law in (17), the control signal $\tau$ can be chosen as [20]:

$$
\tau=I_{m w}\left(\dot{q}_{2}^{d}+K_{3} e_{2}+K_{4} \dot{e}_{2}\right)+\iota_{1}
$$

Where $K_{3}>$ land $K_{4}>1$ are the linear $\mathrm{PD}$ gains, and $u_{1}$ is a nonlinear term to guarantee $\dot{V} \leq 1$ while not $\dot{V}_{2} \leq 1$ itself. Take the derivative of $V_{2}$ and substitute (25), (26) and (28), we have: 


$$
\begin{aligned}
& \dot{V}_{2}=\zeta_{3} e_{2} \dot{e}_{2}+\dot{\prime}_{2} \ddot{e}_{2} \\
& =\boldsymbol{K}_{3} e_{2} \dot{e}_{2}+\dot{ }_{2}\left(\ddot{q}_{2}+{ }^{\prime}{ }_{m w}^{-}(g-\tau)\right. \\
& =\zeta_{3} e_{2} \dot{e}_{2}+\dot{r}_{2}\left\{\ddot{q}_{2}+{ }^{\prime}{ }_{m w}\left[g-{ }_{m w}\left(\ddot{q}_{2}{ }^{d}+\boldsymbol{\zeta}_{3} e_{2}+\boldsymbol{\zeta}_{4} \dot{e}_{2}\right)-{ }_{1}\right]\right\} \\
& \leq \boldsymbol{I}_{3} e_{2} \dot{e}_{2}+\dot{i}_{2}\left(-{ }_{3} e_{2}-r_{4} \dot{e}_{2}\right)+{ }_{m w}^{-} \dot{e}_{2}\left(\beta-i_{1}\right) \\
& =-r_{-4}\left\|\dot{e_{2}}\right\|^{2}+{ }_{m w}^{-} \dot{e}_{2}\left(\beta-i_{1}\right)
\end{aligned}
$$

Finding $\dot{V}_{3}$ is not a straightforward task because $\dot{V}_{3}$ in (23) is a function of the fictitious control law $\phi$. As shown in (21), $\phi$ is a function of desired link acceleration, link position error, link velocity error and bounded function $\rho$. Therefore, the derivative of $V_{3}$ introduces link acceleration error which can be very difficult to measure. The following calculation is targeted at eliminating the link acceleration error term.

We can consider the simple form of $\dot{V}_{3}$

$$
\dot{V}_{3}=q_{2}-\phi \dot{q_{2}}-\dot{\phi}
$$

$\dot{V}$ can be formed by combining (29), (30) and (24), that is:

$$
\begin{aligned}
& \left.\dot{V} \leq-r_{2}\left\|\dot{e}_{1}\right\|^{2}-J_{l}\right)^{-} K_{s 1} N \dot{e}_{1}\left(q_{2}-\phi-r_{4}\left\|\dot{e}_{2}\right\|^{2}+{ }_{m w}^{r-} \dot{e}_{2}\left(\beta-i_{1}\right)+q_{2}-\phi \dot{q_{2}}-\dot{\phi}\right. \\
& \left.\left.=-r_{2}\left\|\dot{e}_{1}\right\|^{2}-r_{4}\left\|\dot{e}_{2}\right\|^{2}+q_{2}-\phi \dot{q_{2}}-\dot{\phi} \cdot J_{l}\right)^{-} K_{s 1} N \dot{e}_{1}\right)+{ }_{m w}^{r-} \dot{e}_{2} \beta-{ }_{m w}^{r-} \dot{e}_{2} u_{1} \\
& \left.\left.\leq-r_{2}\left\|\dot{e}_{1}\right\|^{2}-r_{4}\left\|\dot{e}_{2}\right\|^{2}+{ }_{. .1} 1_{2}-\phi_{.}\left\|\dot{q}_{2}\right\|+\underset{\|}{\|}+J_{l}\right)^{-} K_{s 1} N\left\|\dot{e}_{1}\right\|\right)+{ }_{m w}^{r-}\left\|\dot{e_{2}}\right\| \beta-{ }_{m w}^{r-} \dot{e}_{2} u_{1}
\end{aligned}
$$

To find $u_{1}, \dot{\phi}$ needs to be calculated first from (21)

$$
\dot{\phi}=\frac{J_{l}}{K_{s 1} N}\left(q_{1}^{d^{(3)}}+K_{1} \dot{e}_{1}+K_{2} \ddot{e}_{1}\right)+\frac{1}{K_{s 1} N} \Delta \dot{f}
$$

From (15) we can calculate $\Delta \dot{f}$

$$
\Delta \dot{f}=K_{11} \dot{q}_{1}+K_{12} \dot{q}_{1}-i K_{13}\left(N q_{2}-q_{1}\right)^{2}\left(N \dot{q}_{2}-\dot{q}_{1}\right)
$$

Substitute (33) into (32) 


$$
\begin{aligned}
\dot{\phi}= & \frac{J_{l}}{K_{s 1} N}\left(q_{1}^{d^{(3)}}+K_{1} \dot{e}_{1}+K_{2} \dot{e}_{1}\right)+\frac{1}{K_{s 1} N}\left[K_{11} \dot{q}_{1}+K_{12} \dot{q}_{1}-K_{13}\left(N q_{2}-q_{1}\right)^{2}\left(N \dot{q}_{2}-\dot{q}_{1}\right)\right] \\
= & \frac{J_{l}}{K_{s 1} N}\left(q_{1}^{d^{(3)}}+K_{1} \dot{e}_{1}+K_{2} \dot{e}_{1}\right)+\frac{1}{K_{s 1} N} K_{11} \dot{q}_{1}+\frac{1}{K_{s 1} N} K_{12} \dot{q}_{1} \\
& -\frac{3}{K_{s 1} N} K_{13}\left(N q_{2}-q_{1}\right)^{2}\left(N \dot{q}_{2}-\dot{q}_{1}\right) \\
= & \frac{J_{l}}{K_{s 1} N}\left(q_{1}^{d^{(3)}}+K_{1} \dot{e}_{1}+K_{2} \dot{e}_{1}\right)+\frac{1}{K_{s 1} N} K_{11} \dot{q}_{1}^{d}-\frac{1}{K_{s 1} N} K_{11} \dot{e}_{1}+\frac{1}{K_{s 1} N} K_{12} \dot{q}_{1}^{d}-\frac{1}{K_{s 1} N} K_{12} \dot{e}_{1} \\
& -\frac{3}{K_{s 1} N} K_{13}\left(N q_{2}-q_{1}\right)^{2}\left(N \dot{q}_{2}-\dot{q}_{1}\right) \\
= & \frac{J_{l}}{K_{s 1} N} q_{1}^{d^{(3)}}+\frac{1}{K_{s 1} N} K_{12} \dot{q}_{1}^{d}+\frac{1}{K_{s 1} N} K_{11} \dot{q}_{1}^{d}-\frac{3}{K_{s 1} N} K_{13}\left(N q_{2}-q_{1}\right)^{2}\left(N \dot{q}_{2}-\dot{q}_{1}\right) \\
& +\frac{1}{K_{s 1} N}\left(J_{l} K_{1}-K_{11}\right) \dot{e}_{1}+\frac{1}{K_{s 1} N}\left(J_{l} K_{2}-K_{12}\right) \dot{e}_{1}
\end{aligned}
$$

Therefore,

$$
\begin{aligned}
\|_{\|} \dot{\prime} & \leq \frac{J_{l}}{K_{s 1} N}\left\|q_{1}^{d^{(3)}}\right\|+\frac{1}{K_{s 1} N}\left[K_{12}\left\|\dot{q}_{1}^{d}\right\|+K_{11}\left\|\dot{q_{1}^{d}}\right\|\right]+\frac{3}{K_{s 1} N} K_{13}\left(N q_{2}-q_{1}\right)^{2}\left\|N \dot{q}_{2}-\dot{q}_{1}\right\| \\
& +\frac{1}{K_{s 1} N}\left\|J_{l} K_{1}-K_{11}\right\| \dot{e_{1}}\left\|+\frac{1}{K_{s 1} N}\right\| J_{l} K_{2}-K_{12}\|\| \dot{e}_{1} \| \\
& \leq \frac{J_{l}}{K_{s 1} N} \sup _{t \geq}\left\|q_{1}^{d^{(3)}}\right\|+\frac{1}{K_{s 1} N} K_{12} \sup _{t \geq}\left\|\dot{q}_{1}^{d}\right\|+\frac{1}{K_{s 1} N} K_{11} \sup _{t \geq}\left\|\dot{q}_{1}^{d}\right\|+\frac{3}{K_{s 1} N} K_{13}\left(N q_{2}-q_{1}\right)^{2}\left\|N \dot{q}_{2}-\dot{q}_{1}\right\| \\
& +\frac{1}{K_{s 1} N}\left\|J_{l} K_{1}-K_{11}\right\|\left\|\dot{e_{1}}\right\|+\frac{1}{K_{s 1} N}\left\|J_{l} K_{2}-K_{12}\right\|\left\|\dot{e}_{1}\right\|
\end{aligned}
$$

The following observations can be made:

- If $J_{l} K_{2}-K_{12}=1$ is satisfied by choosing $K_{2}=\frac{K_{12}}{J_{l}}, \dot{e}_{1}$ can be eliminated.

- Because the flexspline elastic displacement is very small (e.g. in $10^{-}$rad range), and can be determined by experiments, we can therefore assume 


$$
\begin{aligned}
& \frac{3}{K_{s 1} N} K_{13}\left(N q_{2}-q_{1}\right)^{2}\left\|N \dot{q}_{2}-\dot{q}_{1}\right\| \text { is small and bounded. Let } \\
& K_{30} \geq \frac{1}{K_{s 1} N}\left[J_{l} \sup \left\|q_{1}^{d^{(3)}}\right\|+K_{12} \sup _{t \geq}\left\|\dot{q}_{1}^{d}\right\|+K_{11} \sup _{t \geq}\left\|\dot{q}_{1}^{d}\right\|\right]+\frac{3}{K_{s 1} N} K_{13}\left(N q_{2}-q_{1}\right)^{2}\left\|N \dot{q}_{2}-\dot{q_{1}}\right\|
\end{aligned}
$$

- Let

$$
K_{31} \geq \frac{1}{K_{s 1} N}\left\|J_{l} K_{1}-\Sigma_{11}\right\|
$$

By applying the above observations to (35), we have:

$$
\left\|\ddot{\phi}_{\|} \leq K_{30}+K_{31}\right\| e^{1} \|
$$

Substitute (36) into (31), and consider $\left\|\dot{q}_{2}\right\| \leq \underset{\|}{\|} \dot{q}_{2}^{d}\left\|+\underset{\|}{\| e_{2}}\right\|$, we have:

$$
\begin{aligned}
& \dot{V} \leq-K_{2}\left\|\dot{e}_{1}\right\|^{2}-K_{4}\left\|\dot{e}_{2}\right\|^{2}+J_{m w}^{-}\left\|\dot{e_{2}}\right\| \| \beta_{n}-J_{m w}^{-} \dot{e}_{2} u_{1} \\
& \left.\left.+q_{2}-\phi_{n}\left\|\dot{q}_{2}^{d}\right\|+e_{\|}\left\|+K_{30}+K_{31}\right\| \dot{e}_{1} \|+J_{l}\right)^{-} K_{s 1} N\left\|\dot{e}_{1}\right\|\right\} \\
& \leq-K_{2}\left\|\dot{e}_{1}\right\|^{2}-K_{4}\left\|\dot{e}_{2}\right\|^{2}+J_{m w}^{-}\left\|\dot{e_{2}}\right\| \| \beta_{n}-J_{m w}^{-} \dot{e}_{2} u_{1} \\
& \left.\left.\left.+{ }_{.2} q_{2}-\phi_{. .}\left(\sup _{t \geq}\left\|\dot{q_{2}^{d}}\right\|+K_{30}\right)+K_{31}+J_{l}\right)^{-} K_{s 1} N\right)\left\|\dot{e}_{1}\right\|+{ }_{\|}^{\| \bullet} e_{2} \|\right\}
\end{aligned}
$$

Ideally, $\left\|\dot{e}_{1}\right\|=N\left\|\dot{e}_{2}\right\|$, therefore we can find a $K_{31}^{\prime}$ to satisfy

$$
\left.K_{31}^{\prime}\left\|\dot{e}_{2}\right\| \geq J_{m w}\left\{\left(K_{31}+J_{l}\right)^{-} K_{s 1} N\right)\left\|\dot{e}_{1}\right\|+{ }_{\|} e_{2} \|\right\}
$$

Let

$$
K_{30}^{\prime} \geq r_{m w}\left(\sup _{t \geq}\left\|\dot{q_{2}^{d}}\right\|+\Sigma_{30}\right)
$$

Equation (37) can be simplified to: 


$$
\begin{aligned}
& \left.\dot{V} \leq-r_{2}\left\|\dot{e}_{1}\right\|^{2}-r_{4}\left\|\dot{e}_{2}\right\|^{2}+{ }_{m w}^{r-}\left\|q_{2}-\phi{ }_{n}^{\prime} K_{30}^{\prime}+r_{31}^{\prime}\right\| e_{2} \|\right)+{ }_{m w}^{r-}\left\|\dot{e}_{2}\right\| \| \beta-{ }_{n}^{r-} \dot{e}_{m w} u_{1} \\
& =-r_{2}\left\|\dot{e}_{1}\right\|^{2}-r_{4}\left\|\dot{e}_{2}\right\|^{2}+{ }_{m w}^{r-} K_{30}^{\prime}\left\|q_{2}-\phi{ }_{n}+{ }_{m w}^{r-} K_{31}^{\prime}\right\| q_{2}-\phi_{r}^{\prime \prime} \dot{e}_{2}\left\|+{ }_{m w}^{r-}\right\| \dot{e_{2}}\|\| \beta_{n}-{ }_{m w}^{-r_{m}^{-}} \dot{e}_{2} u_{1}
\end{aligned}
$$

We can choose nonlinear term $u_{1}$ in the form of

$$
u_{1}=\frac{K_{33} \dot{e}_{2}}{\left\|\dot{e}_{2}\right\|+K_{32}}\left(K_{30}^{\prime}\left\|q_{2}-{ }_{. .}+K_{31}^{\prime}\right\| q_{2}-i_{.}+{ }_{\text {. }} \beta_{\text {." }}\right.
$$

Substitute (41) into (40), the final $\dot{V}$ is

$$
\begin{aligned}
\dot{V} \leq & \left.-K_{2}\left\|\dot{e_{1}}\right\|^{2}-K_{4}\left\|\dot{e}_{2}\right\|^{2}+J_{m w}^{-} K_{30}^{\prime} \| q_{2}-i_{n} 1-\frac{K_{33}\left\|\dot{e}_{2}\right\|^{2}}{\left\|\dot{e_{2}}\right\|+K_{32}}\right) \\
& +J_{m w}^{-}\left(\left\|\dot{e}_{2}\right\|-\frac{K_{33}\left\|\dot{e}_{2}\right\|^{2}}{\left\|\dot{e_{2}}\right\|+K_{32}}\right)\left(K_{31}^{\prime} \| q_{2}-i_{n}+{ }_{n} \beta_{n}\right.
\end{aligned}
$$

In order to satisfy the above inequity, let $K_{33}>1$ and $K_{32}<\underset{\|}{-e_{2}} \|$. And

$$
\begin{aligned}
\dot{V}= & \left.-K_{2}\left\|\dot{e_{1}}\right\|\left\|^{2}-K_{4}\right\| \dot{e}_{2}\left\|^{2}+J_{m w}^{-} K_{30}^{\prime}\right\| q_{2}-\frac{\left\|\dot{e_{2}}\right\|+K_{32}-K_{33}\left\|\dot{e}_{2}\right\|^{2}}{\left\|\dot{e}_{2}\right\|+K_{32}}\right) \\
& +J_{m w}^{-}\left(\frac{\left\|\dot{e}_{2}\right\|^{2}+K_{32}\left\|\dot{e}_{2}\right\|-K_{33}\left\|\dot{e}_{2}\right\|^{2}}{\left\|\dot{e}_{2}\right\|+K_{32}}\right)\left(K_{31}^{\prime} \| q_{2}-i_{n}+{ }_{" \prime}\right.
\end{aligned}
$$

Because $K_{32}$ and $K_{33}$ are control parameters, we can choose suitable values to ensure 


$$
\begin{aligned}
& K_{33}\left\|\dot{e}_{2}\right\|^{2} \geq \dot{e}_{2} \|+K_{32} \\
& K_{33}\left\|\dot{e}_{2}\right\|^{2} \geq \dot{e}_{2}\left\|^{2}+K_{32}\right\| \dot{e}_{2} \|
\end{aligned}
$$

Therefore, we can achieve $\dot{V} \leq 1$. This implies uniformly ultimate bounded stability given the fact that $K_{33}$ increases as $e_{2}$ decreases. Substitute (41) into (28), the final control torque is:

$$
\tau=J_{m w}\left(\dot{q}_{2}^{d}+K_{3} e_{2}+K_{4} \dot{e}_{2}\right)+\frac{K_{33} \dot{e}_{2}}{\left\|\dot{e}_{2}\right\|+K_{32}}\left(K_{30}^{\prime}\left\|q_{2}-i_{"}+K_{31}^{\prime}\right\| q_{2}-i_{"}+{ }_{\text {" }} \beta_{\text {" }}\right.
$$

For MRR, the configuration change presents a new set of robot dynamic parameters. Hence, decentralized control is a suitable strategy to handle motion tracking of MRR. In decentralized control, every joint is treated as a single input single output (SISO) system

plus a disturbance torque representing all uncertainties of the robot. In equation (43), $K_{33}$ and $K_{32}$ are control parameters; $K_{30}^{\prime}, K_{31}$ and $\beta$ are determined based on the upper bound on the link/motor dynamics. Therefore, (43) does not directly depends on the link parameters and will require minimal (or no) change of control parameters when robot is reconfigured. The proposed control law is a saturation type controller because of the bounded nonlinear term $u_{1}$.

\section{EXPERIMENT}

The performance of the proposed robust controller was evaluated using a three degree of freedom (DOF) modular and reconfigurable robot (MRR) controlled by a MSK2812 DSP kit. For every DOF, joint parameter identification was performed according to the procedure described in [35]. Two different configurations with and without load were set up. For each case, the MRR was controlled to follow sinusoidal trajectories in joint space using the same set of control parameters. The experimental setup and results are presented in this section. 


\section{MRR System}

The MRR system block diagram is shown in Fig. 2. Block diagram of MRRFig. 2. All three joints are connected with DSP via controller area network (CAN) communication bus, and the DSP is connected with a PC through RS232. Each joint accepts the torque command transmitted on the CAN based on its own ID, and sends the motor and link position/velocity signals back to DSP for both closed loop control and data collection. This data can be uploaded to a PC offline. Because of the limit of CAN bus, the control frequency is less than standard $500 \mathrm{~Hz}$. The desired trajectory for each joint is in the form of:

$$
\operatorname{Traj}=1 \sin \left(\frac{2 \pi}{T} *\left(\frac{j}{f}\right)\right)
$$

Where, $A=10 \mathrm{deg}$ is the trajectory amplitude, $T={ }^{\prime} s$ is the trajectory period, $f=0 \mathrm{~Hz}$ is the control frequency, and $j=1,1, \ldots$ is the control signal index. Fig. 3 and Fig. 4Error! Reference source not found. show the desired trajectories of both configurations in the task space. These trajectories map to sinusoidal trajectories for each joint in joint space. Fig. 5 and Fig. 6 show two different MRR configurations. For each configuration, two tasks were tested under load and no load conditions. The load is in the form of a wrist assembly that weighs $201 \mathrm{~b}$ as shown in Fig. 5 and Fig. 6.

\section{Experiment Results}

Parameters of the proposed controller were tuned to reduce the trajectory tracking error based on the first configuration without load, while satisfying the constraints described in Section III. We first tuned PD gains, $K_{3}$ and $K_{4}$ in equation (43), to achieve a desirable tracking performance. Then the nonlinear term was added to compensate disturbances and tuned to achieve the desired trajectory tracking performance. These same set of parameters were then applied to all other experiments, i.e. with load and for the second configuration. The parameters are listed in Table. I. $k_{i j}, i=, 2$ and $j=, 2,3,4$, were not shown in this table, because they were calculated from equation (16) and (17), respectively. The mean squared error (MSE) shown in equation (45) was used to evaluate the MRR trajectory tracking performance. Equation (46) was used to calculate the 
improvement of the proposed robust controller compared to PID controller. The results are summarized in Tables II and III for both configurations.

$$
M S E_{i}=\frac{\sum_{\nu=}\left(q_{a_{i j}}-1_{a_{i j}}\right)^{2}}{N}
$$

Where $\mathrm{N}$ is the number of sampled data, $i=, 2,3$ refers $i^{t h}$ joint, and $q_{a_{i j}}$ and $M_{a_{i j}}$ are the measured position errors and mean of those errors of each joint, respectively.

$$
\text { improvement }=\frac{P I D(M S E)-\text { Robust }(M S E)}{P I D(M S E)} \times 00 \%
$$

From Table II, it can be shown that for configuration 1 the proposed robust controller outperformed the well-tuned linear controller for all three degrees of freedom. For the given trajectory in Fig. 3 and Fig. 4Error! Reference source not found., the improvement in performance at no load is $38.92 \%, 8.93 \%$ and $27.20 \%$ for joints 1,2 , and 3 respectively. For a payload of $20 \mathrm{Lb}$ in the form of an end point wrist assembly, the improvement in performance using the robust controller is $16.35 \%, 14.92 \%$, and $5.04 \%$ for joints 1, 2, and 3 respectively. Under reconfiguration, all control parameters in Table I were kept unchanged. The robust control still outperformed the industrial linear control for the configuration 2 shown in Fig. 6. For the trajectory shown in Fig. 3 and Fig. 4Error! Reference source not found., the robust control showed an improvement in tracking performance of $12.17 \%$ for joint $1,16.24 \%$ for joint 2 and $45.53 \%$ for joint 3 at no load. With a $20 \mathrm{Lb}$ end point load, the improvement in tracking performance is $6.91 \%$ for joint $1,11.79 \%$ for joint 2 and $26.26 \%$ for joint 3 . The percentage improvements in workspace tracking using the proposed controller compared to PID controller for a $20 \mathrm{Ib}$ end point load are summarized in Table 4.

During experiments it was observed that the first joint is the most rigid compared to others, and the third joint generated more vibrations because of dynamic interactions with other degrees of freedom joints. Fig. 7 - Fig. 18 show the torque signals of each joint of both configurations under different tasks.

\section{CONCLUSION}


In this paper, a decentralized robust controller is presented for a modular and reconfigurable robot (MRR) that uses a harmonic drive transmission system. The uncertainty compensation and good position tracking performance is achieved by fusing a linear PD controller with a saturated type robust control law. In order to precisely control the MRR, the nonlinear property of HD flexspline compliance was introduced into the joint dynamics (6) (7). The important features of the controller are the simplicity in computation compared with a centralized controller, and greater disturbance tolerance which can be observed from the successful position tracking during experimental analysis.

\section{APPENDIX}

\section{SINGLE JOINT DYNAMIC}

The detailed derivations of the single joint dynamic equations of (3) (4) and (5) are shown in this appendix. The single joint with HD can be modeled as a mass-spring system as shown in Fig. 7, and it is considered as three subsystems: 1) input subsystem; 2) transmission subsystem; and 3) output subsystem. All the notations can be found in Section II.

\section{A. Input subsystem}

The input subsystem consists of motor and HD wave-generator, based on Euler-Lagrange equation, we have:

- Kinetic energy: $\quad K=\frac{1}{2} J_{m w} \dot{q}_{2}^{2}$

- Potential energy: $P=1$

- Lagrangian: $L=K-P=\frac{1}{2} J_{m w} \dot{q}_{2}^{2}$

Therefore the resulting torque can be calculated as: 


$$
\tau_{,}=\frac{d}{d t} \frac{\partial L}{\partial \dot{q}_{2}} \cdot-\frac{\partial L}{\partial q_{2}}=J_{m w} \dot{q}_{2}
$$

This resulting torque $\tau$, is also related to motor input torque $\tau$, friction torque and flexspline stiffness torque exerted on the input side. The following equation is satisfied:

$$
\tau_{\imath}=\cdot-\left(F_{m d} \dot{q}_{2}+\vec{r}_{m s} \operatorname{sign}\left(\dot{q_{2}}\right)\right)-\vee \tau_{j}
$$

Therefore, the input subsystem dynamic equation is:

$$
J_{m w} \dot{q}_{2}+F_{m d} \dot{q}_{2}+F_{m s} \operatorname{sign}\left(\dot{q_{2}}\right)+N \tau_{f}=.
$$

\section{B. Transmission subsystem}

The transmission subsystem refers to the flexible HD flexspline which is usually run at low speed, and its mass can be ignored. Two types of flexspline models are widely used, piece-wise linear [37] and nonlinear [36]. We have setup experiments to calibrate the flexspline stiffness coefficients, and found that a nonlinear model better represents the flexspline dynamics. The experiments and results are out of the scope of this paper. The flexspline dynamics is in the following form:

$$
\tau=r_{s 1}\left(N q_{2}-i_{1}\right)+r_{s 2}\left(N q_{2}-i_{1}\right)^{3}
$$

\section{Output subsystem}

The link and load together form the output subsystem. The link generates great effects on the robot dynamics. In comparison with the unexpected load which is exerted at the end of the link, the link mass is very small. Therefore, we assume the link mass $m$ is centered at the end of the link as shown in Fig. 7. Based on the Euler-Lagrange equation:

- Kinetic energy: $K=\frac{1}{2} J_{l} \dot{q}_{1}^{2}$

- Potential energy: $P=-i g l \cos \left(q_{1}\right)$

- Lagrangian: $\quad L=K-{ }^{\supset}=\frac{1}{2} J_{l} \dot{q}_{1}^{2}+\eta g l \cos \left(q_{1}\right)$ 
The resulting torque is:

$$
\tau=\frac{l}{d t} \frac{\partial}{\partial \dot{r}_{1}} \cdot-\frac{\partial}{\partial{ }_{1}}={ }_{l} \dot{q}_{1}+\operatorname{rag} \sin \left(q_{1}\right)
$$

The resulting torque $\tau$ comes from the torsional torque applied by the flexspline, friction torque and disturbance, which can be expressed as:

$$
\tau={ }_{j}-\left(F_{l d} \dot{q_{1}}+\vec{i}_{l s} \operatorname{sign}\left(\dot{q_{1}}\right)\right)-
$$

So the output dynamics is

$$
\left.J_{l} \dot{q}_{1}+\operatorname{mgl} \operatorname{sign}\left(q_{1}\right)+F_{l d} \dot{q}_{1}+F_{l s} \operatorname{sign}\left(\dot{q}_{1}\right)\right)+\tau,+\tau_{j}=1
$$

Finally, we can rearrange (49), (50), (53) into two equation representing single joint dynamics in (6) and (7). 
Table 1

ROBUST CONTROLLER PARAMETERS

\begin{tabular}{|c|c|c|c|c|c|c|}
\hline & \multicolumn{2}{|c|}{ Linear parameters } & \multicolumn{4}{|c|}{ Nonlinear parameters } \\
\hline Joint & $K_{3}$ & $K_{4}$ & $K_{30}$ & $K_{31}$ & $K_{32}$ & $K_{33}$ \\
\hline$\# 1$ & 0.25 & 0.025 & 0.1 & 0.2 & 1 & 0.12 \\
\hline$\# 2$ & 0.15 & 0.005 & 0.1 & 0.1 & 1 & 0.8 \\
\hline$\# 3$ & 0.35 & 0.025 & 0.1 & 0.2 & 0.01 & 0.3 \\
\hline
\end{tabular}

Table 2

CONFIG 1: PID vs ROBUST

\begin{tabular}{|c|c|c|c|c|c|c|}
\hline \multirow{2}{*}{ Joint } & \multicolumn{3}{|c|}{ No load (position MSE) } & \multicolumn{3}{c|}{ Load 20lb (position MSE) } \\
\cline { 2 - 7 } & $\begin{array}{c}\text { PID } \\
\left(\mathrm{deg}^{2}\right)\end{array}$ & $\begin{array}{c}\text { Robust } \\
\left(\mathrm{deg}^{2}\right)\end{array}$ & $\begin{array}{c}\text { Improve } \\
(\%)\end{array}$ & $\begin{array}{c}\text { PID } \\
\left(\mathrm{deg}^{2}\right)\end{array}$ & $\begin{array}{c}\text { Robust } \\
\left(\mathrm{deg}^{2}\right)\end{array}$ & $\begin{array}{c}\text { Improve } \\
(\%)\end{array}$ \\
\hline$\# 1$ & 1.4445 & 0.8823 & 38.92 & 1.1562 & 0.9672 & 16.35 \\
\hline$\# 2$ & 1.8327 & 1.3025 & 28.93 & 2.7272 & 2.3202 & 14.92 \\
\hline$\# 3$ & 1.0856 & 0.7903 & 27.20 & 1.9009 & 1.8052 & 5.04 \\
\hline
\end{tabular}

Table 3

CONFIG 2: PID vs ROBUST

\begin{tabular}{|c|c|c|c|c|c|c|}
\hline \multirow{2}{*}{ Joint } & \multicolumn{3}{|c|}{ No load (position MSE) } & \multicolumn{3}{c|}{ Load 20lb (position MSE) } \\
\cline { 2 - 7 } & $\begin{array}{c}\text { PID } \\
\left(\mathrm{deg}^{2}\right)\end{array}$ & $\begin{array}{c}\text { Robust } \\
\left(\mathrm{deg}^{2}\right)\end{array}$ & $\begin{array}{c}\text { Improve } \\
(\%)\end{array}$ & $\begin{array}{c}\text { PID } \\
\left(\mathrm{deg}^{2}\right)\end{array}$ & $\begin{array}{c}\text { Robust } \\
\left(\mathrm{deg}^{2}\right)\end{array}$ & $\begin{array}{c}\text { Improve } \\
(\%)\end{array}$ \\
\hline$\# 1$ & 0.9900 & 0.8695 & 12.17 & 1.6999 & 1.5825 & 6.91 \\
\hline$\# 2$ & 1.9590 & 1.6409 & 16.24 & 3.8442 & 3.3910 & 11.79 \\
\hline$\# 3$ & 2.3647 & 1.2880 & 45.53 & 4.6938 & 3.4610 & 26.26 \\
\hline
\end{tabular}

Table 4

Percentage Improvement of tracking In Workspace coordinates

\begin{tabular}{|c|c|c|c|c|c|c|c|}
\hline Config. & Load & $\begin{array}{c}\text { Position } \\
(\mathrm{X}) \%\end{array}$ & $\begin{array}{c}\text { Position } \\
(\mathrm{Y}) \%\end{array}$ & $\begin{array}{c}\text { Position } \\
(\mathrm{Z}) \%\end{array}$ & $\begin{array}{c}\text { Rotation } \\
(\mathrm{X}) \%\end{array}$ & $\begin{array}{c}\text { Rotation } \\
(\mathrm{Y}) \%\end{array}$ & $\begin{array}{c}\text { Rotation } \\
(\mathrm{Z}) \%\end{array}$ \\
\hline & $20 \mathrm{Ib}$ & 25.97 & 15.57 & 12.28 & -5.62 & 28.19 & 6.50 \\
\hline & $20 \mathrm{Ib}$ & 35.66 & 21.01 & 47.14 & 27.75 & 22.44 & 30.38 \\
\hline
\end{tabular}




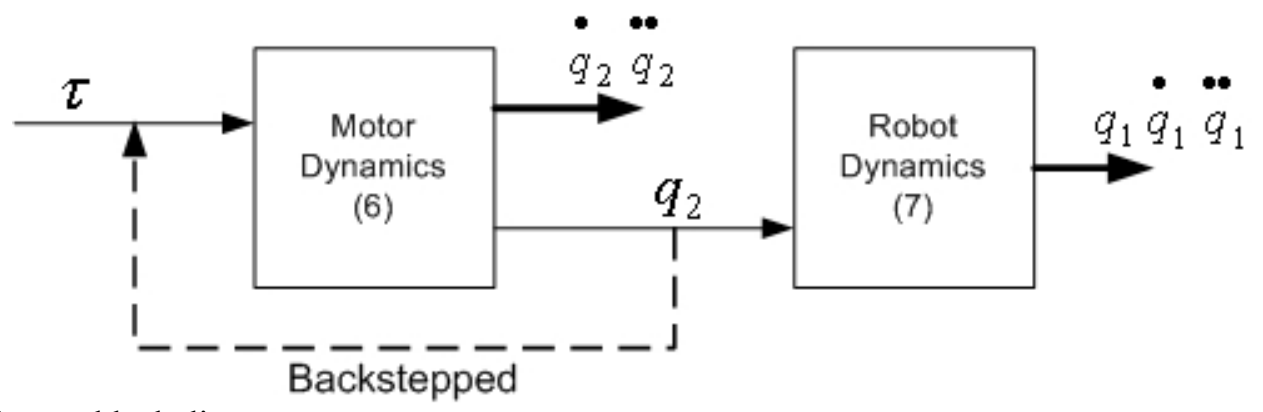

Fig. 1. System block diagram

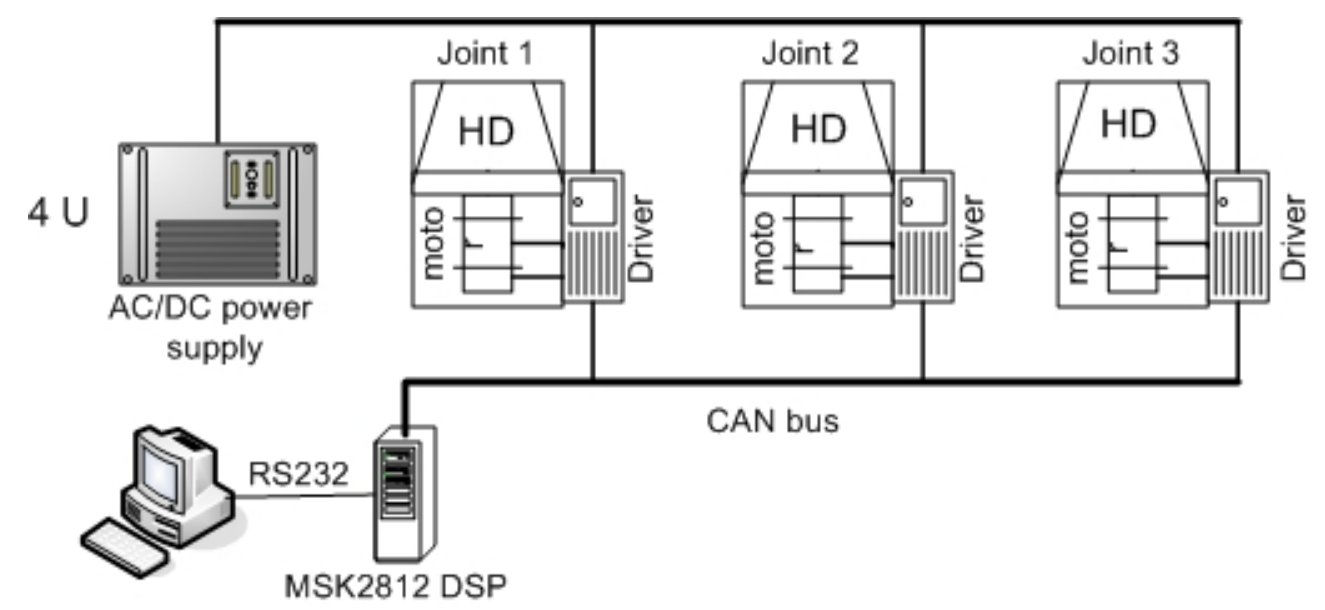

Fig. 2. Block diagram of MRR 

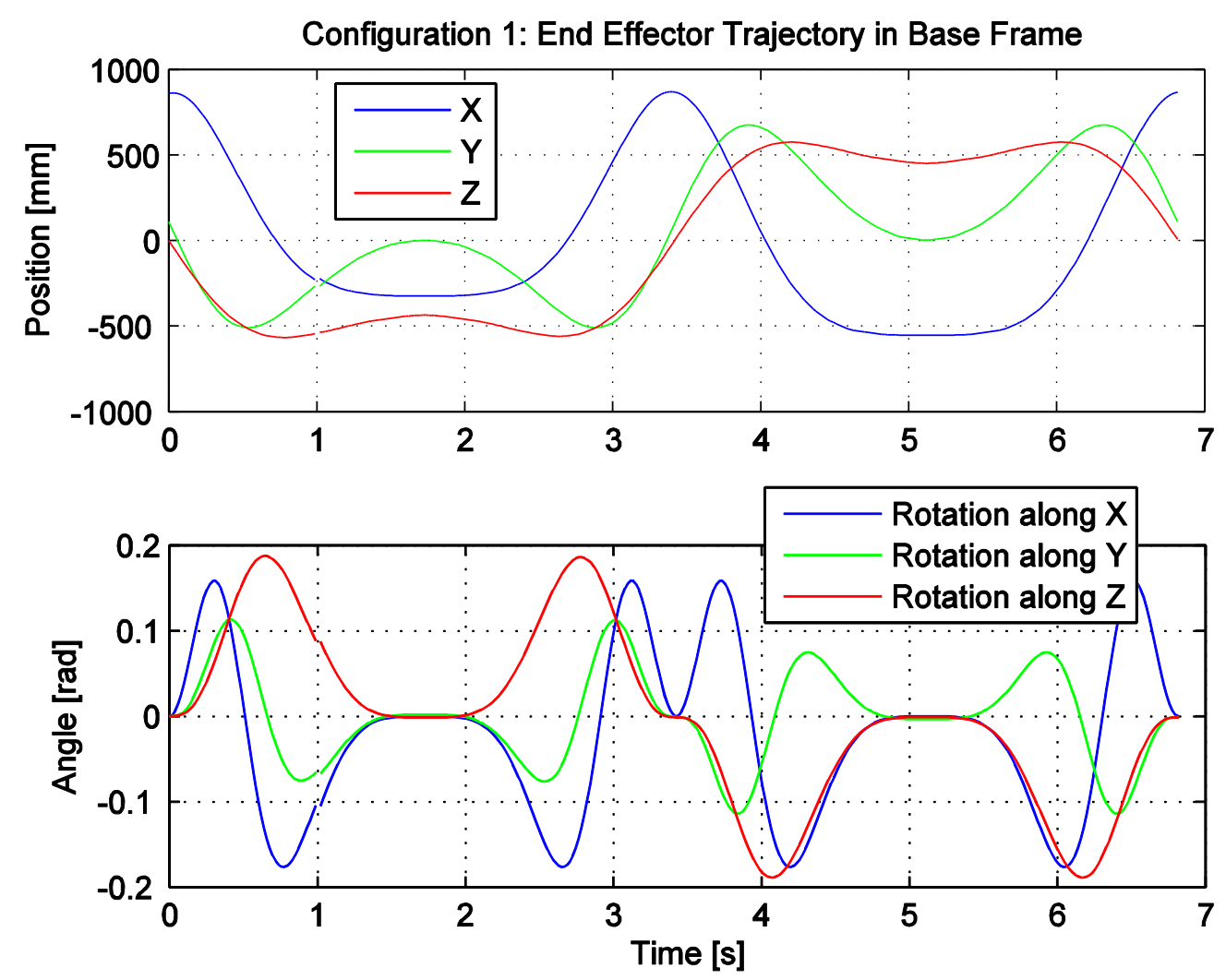

Fig. 3 Configuration 1 end effector trajectory in workspace 

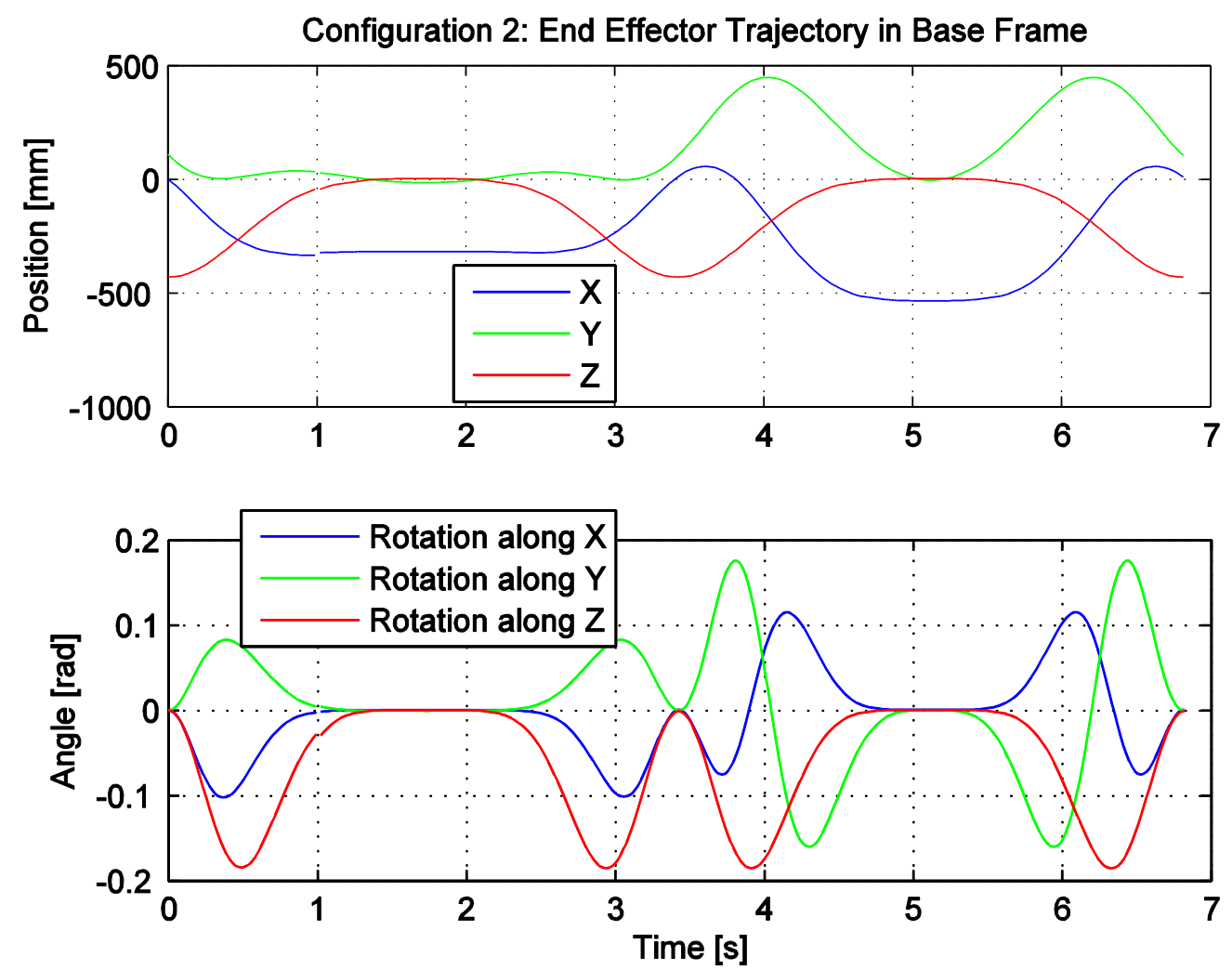

Fig. 4 Configuration 2 end effector trajectory in work space 


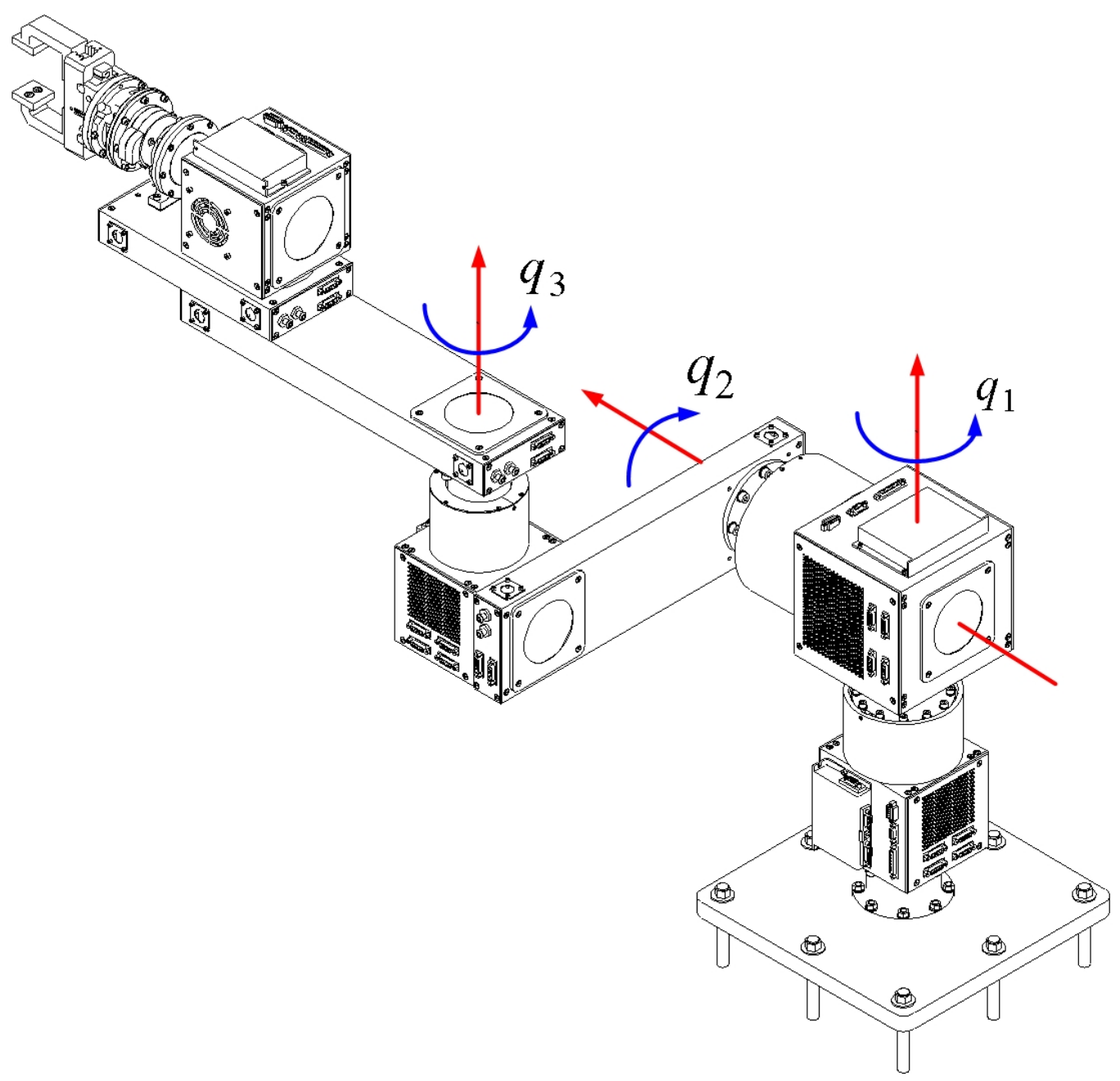

Fig. 5. Configuration 1: with load

Fig. 6. Configuration 2: with load 


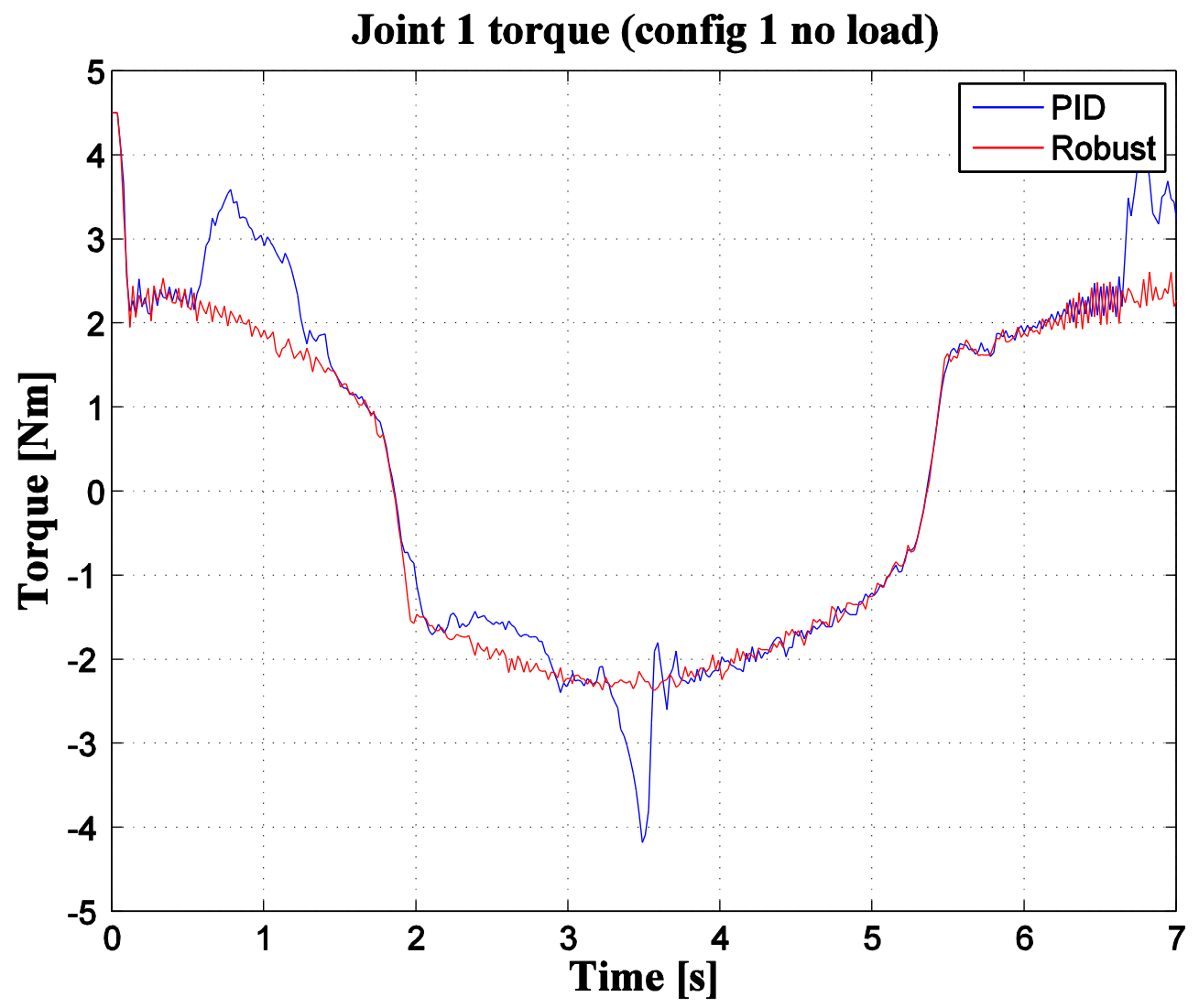

Fig. 7. joint 1 torque (config 1 no load) 


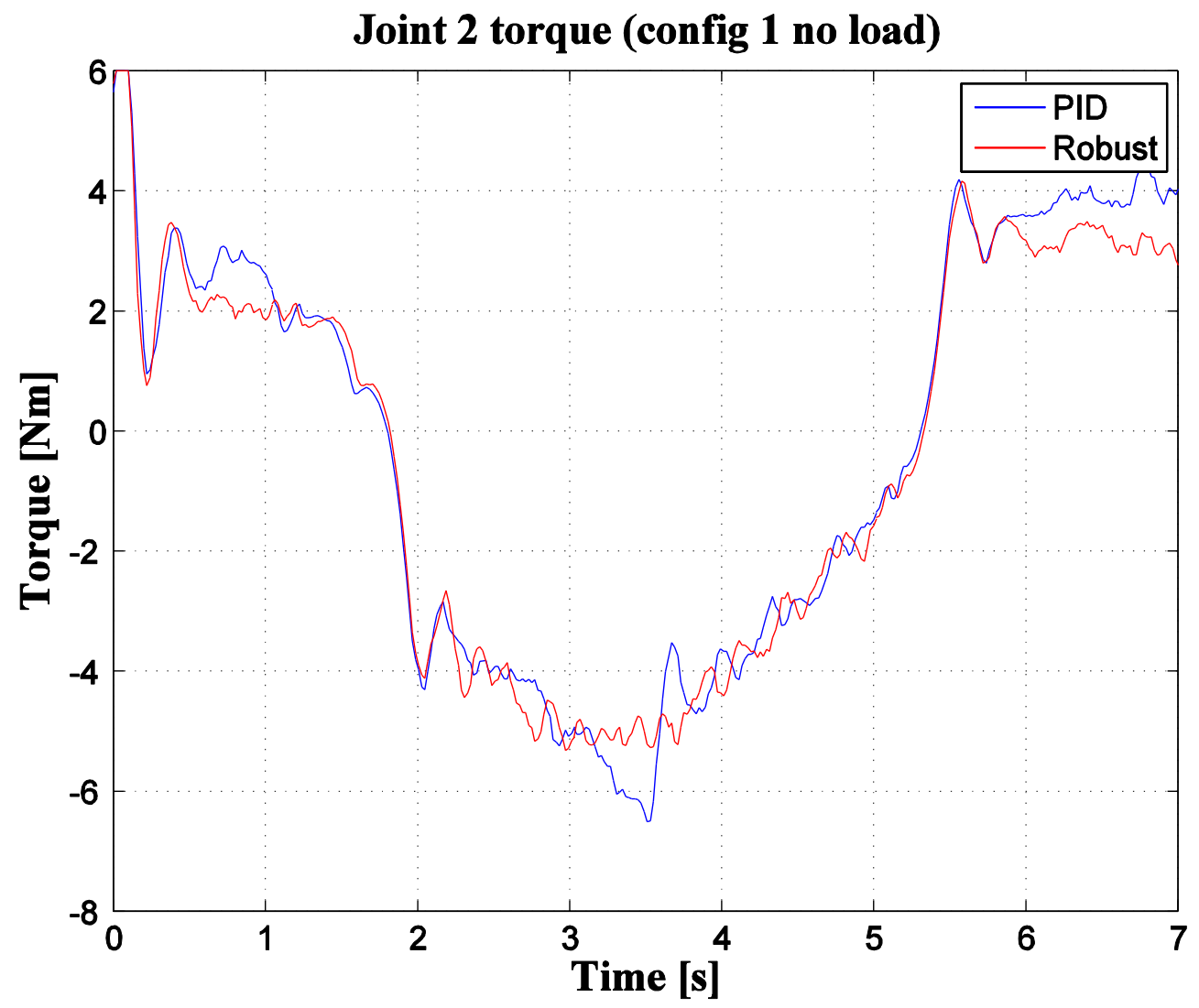

Fig. 8. joint 2 torque (config 1 no load) 


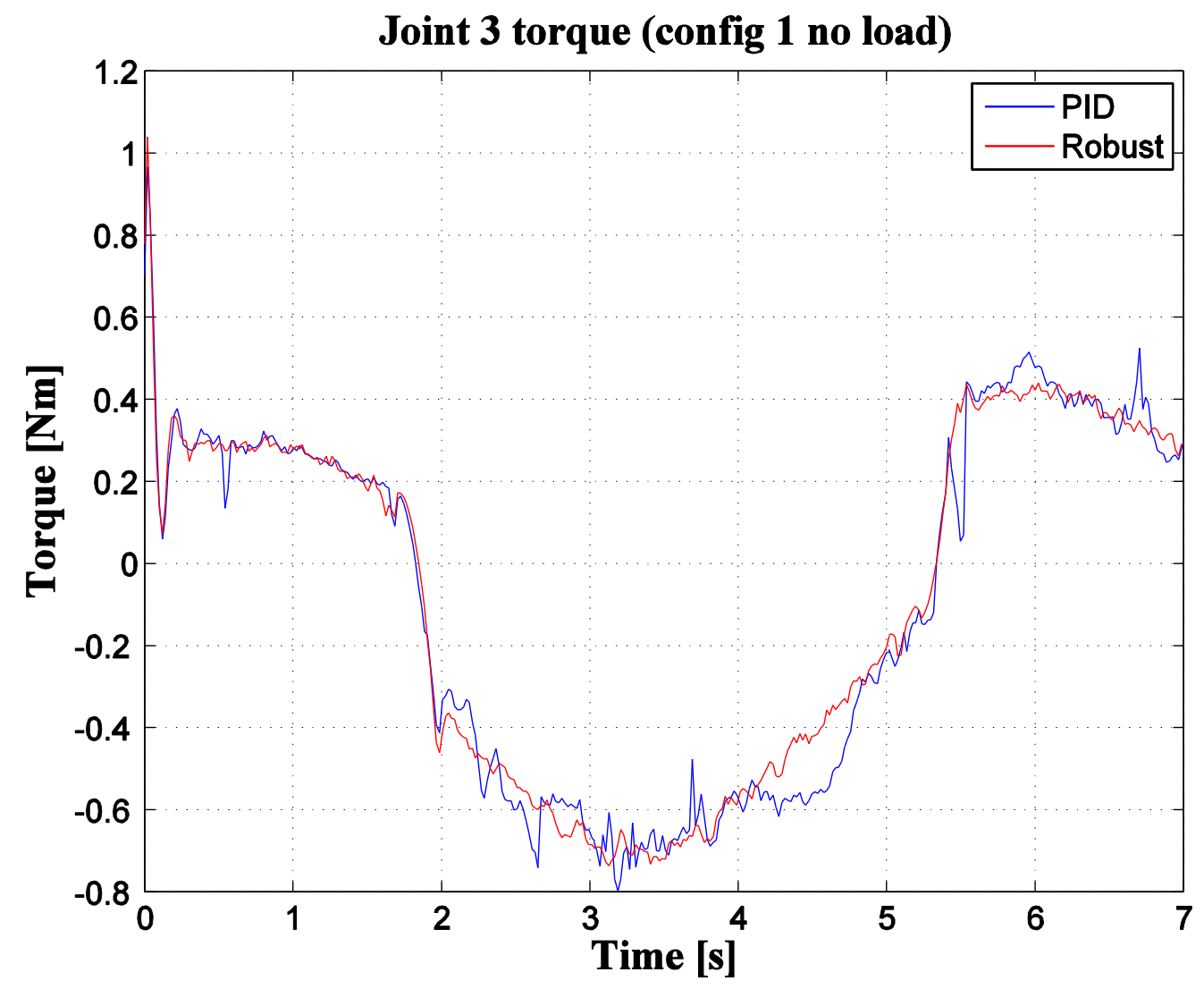

Fig. 9. joint 3 torque (config 1 no load) 


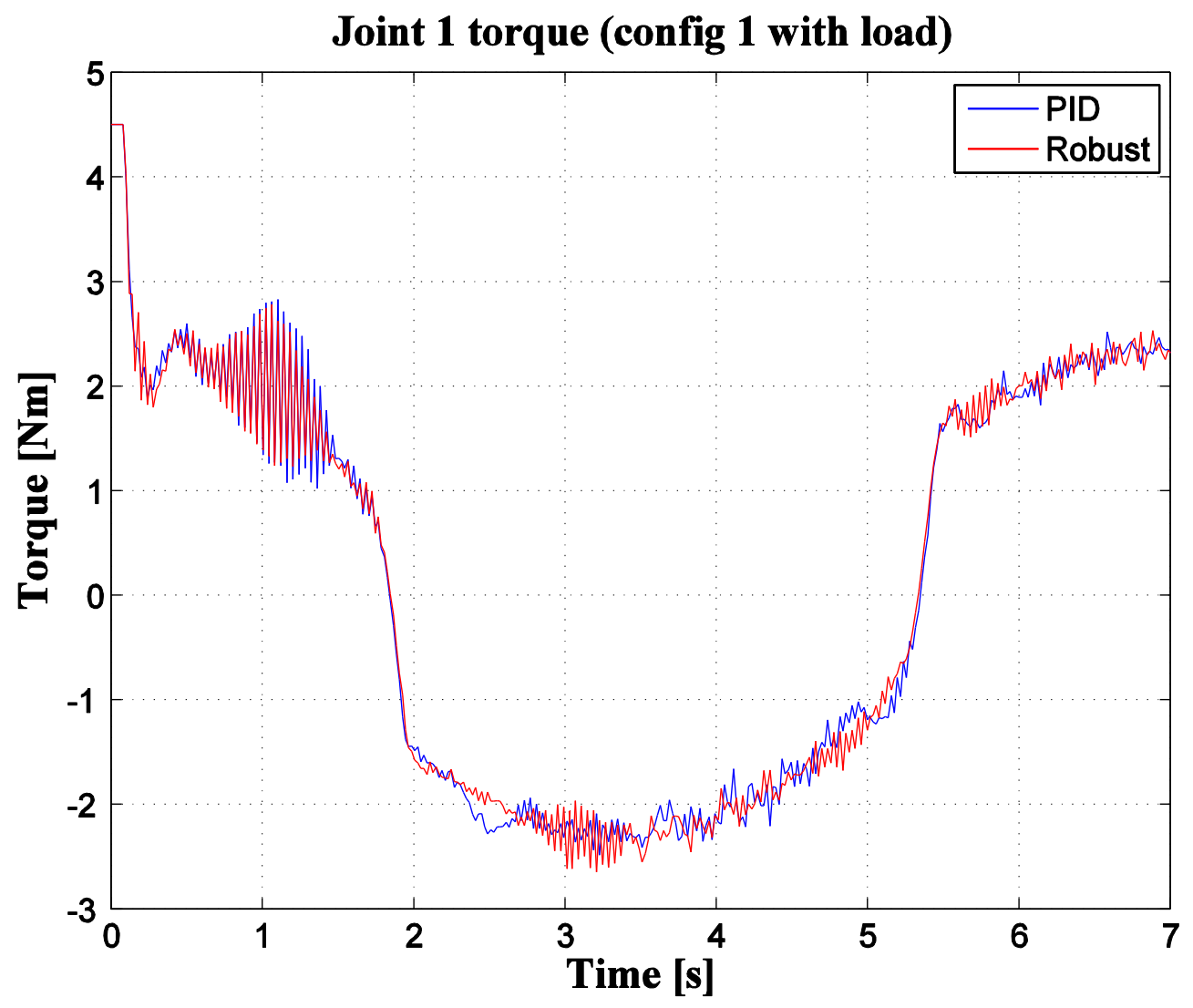

Fig. 10. joint 1 torque (config 1 with load) 


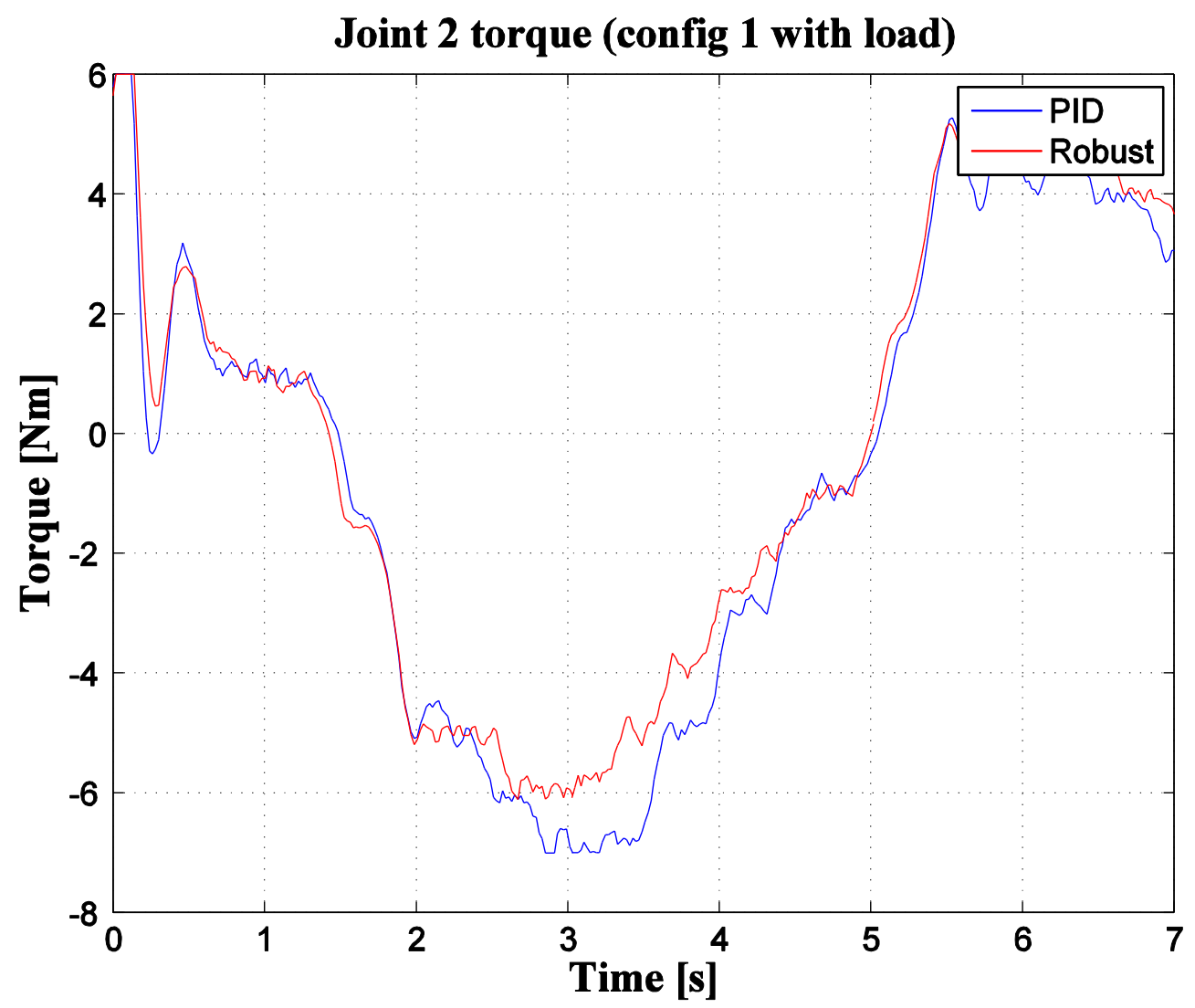

Fig. 11. joint 2 torque (config 1 with load) 


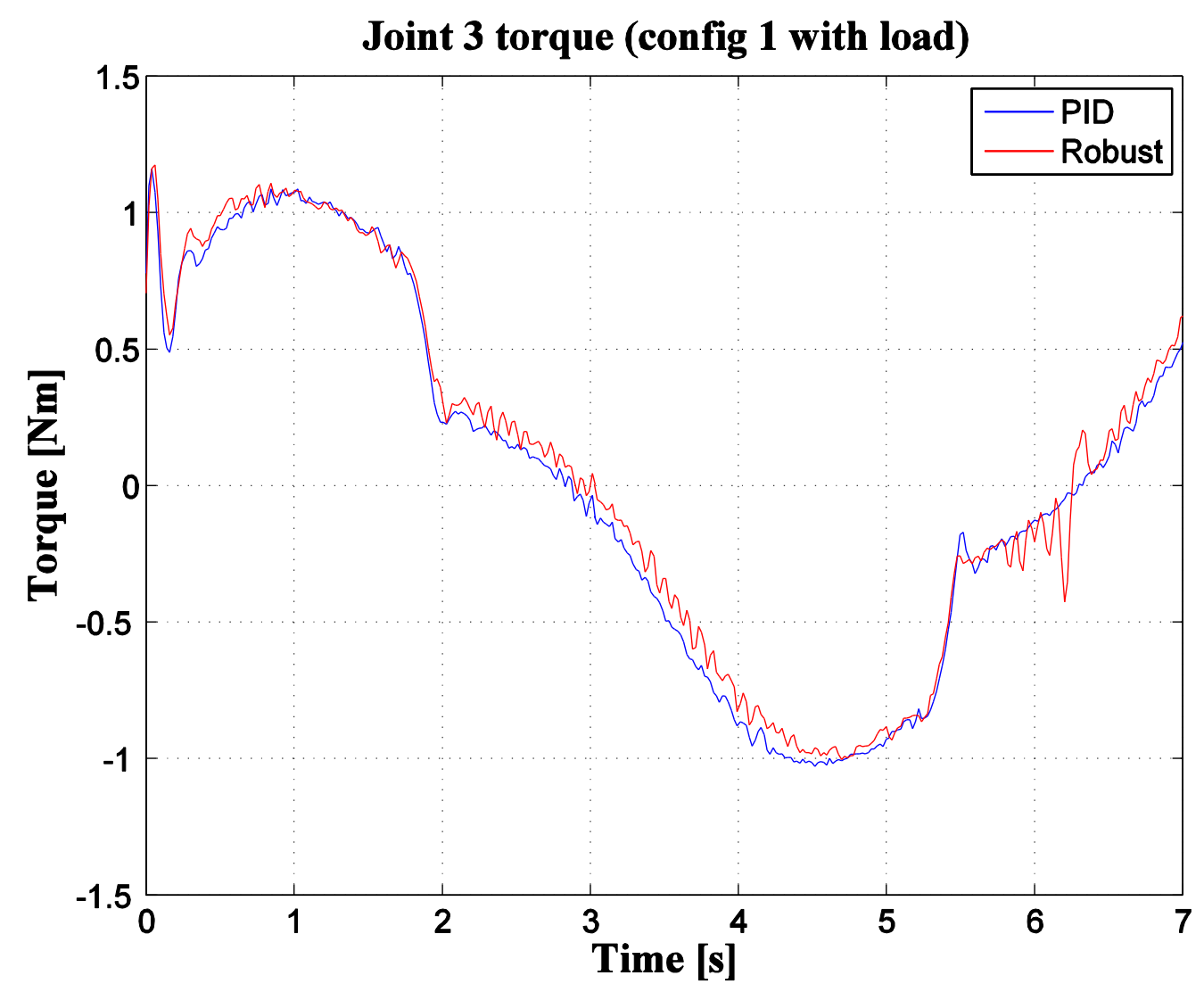

Fig. 12. joint 3 torque (config 1with load) 


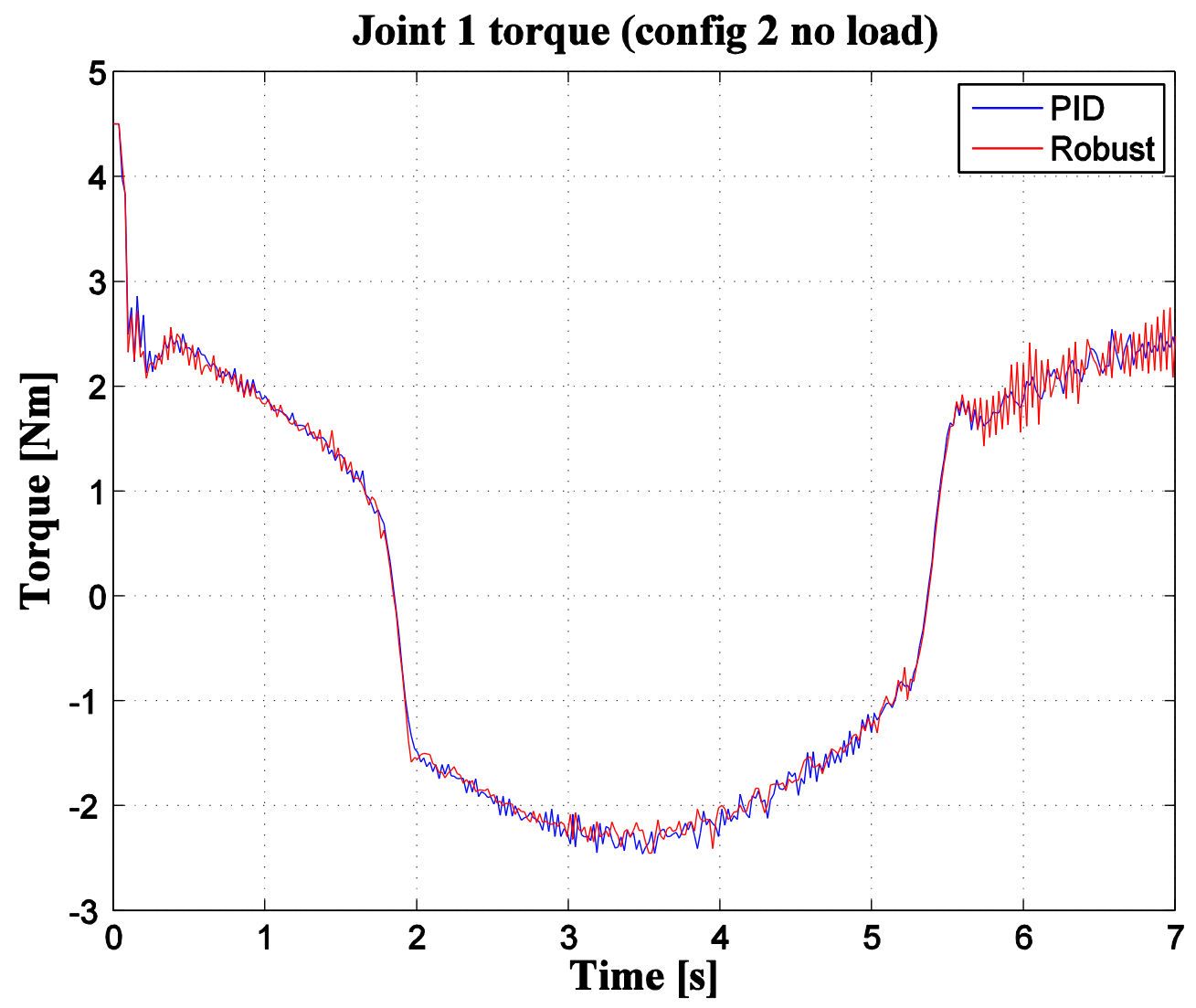

Fig. 13. joint 1 torque (config 2 no load) 


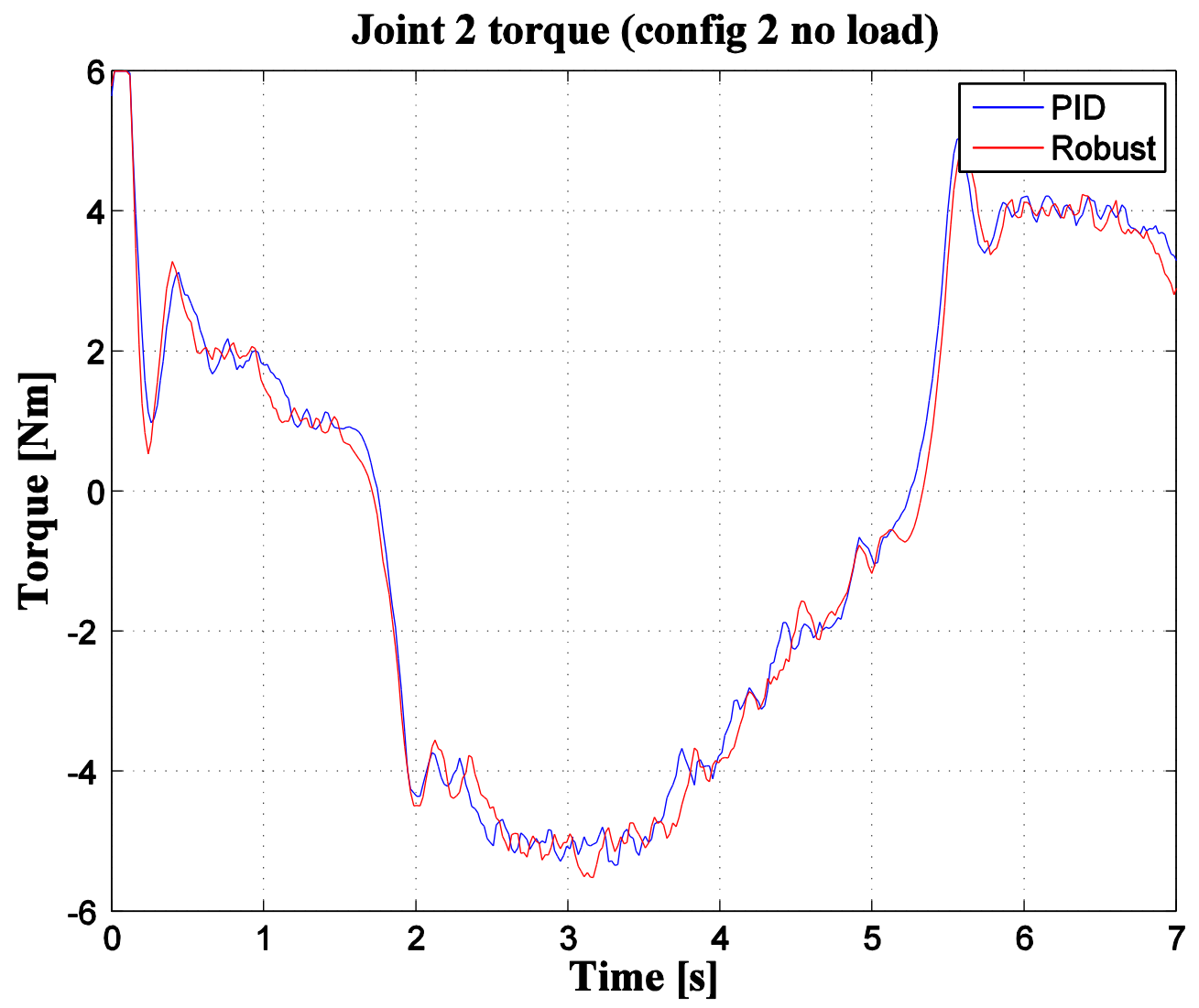

Fig. 14. joint 2 torque (config 2 no load) 


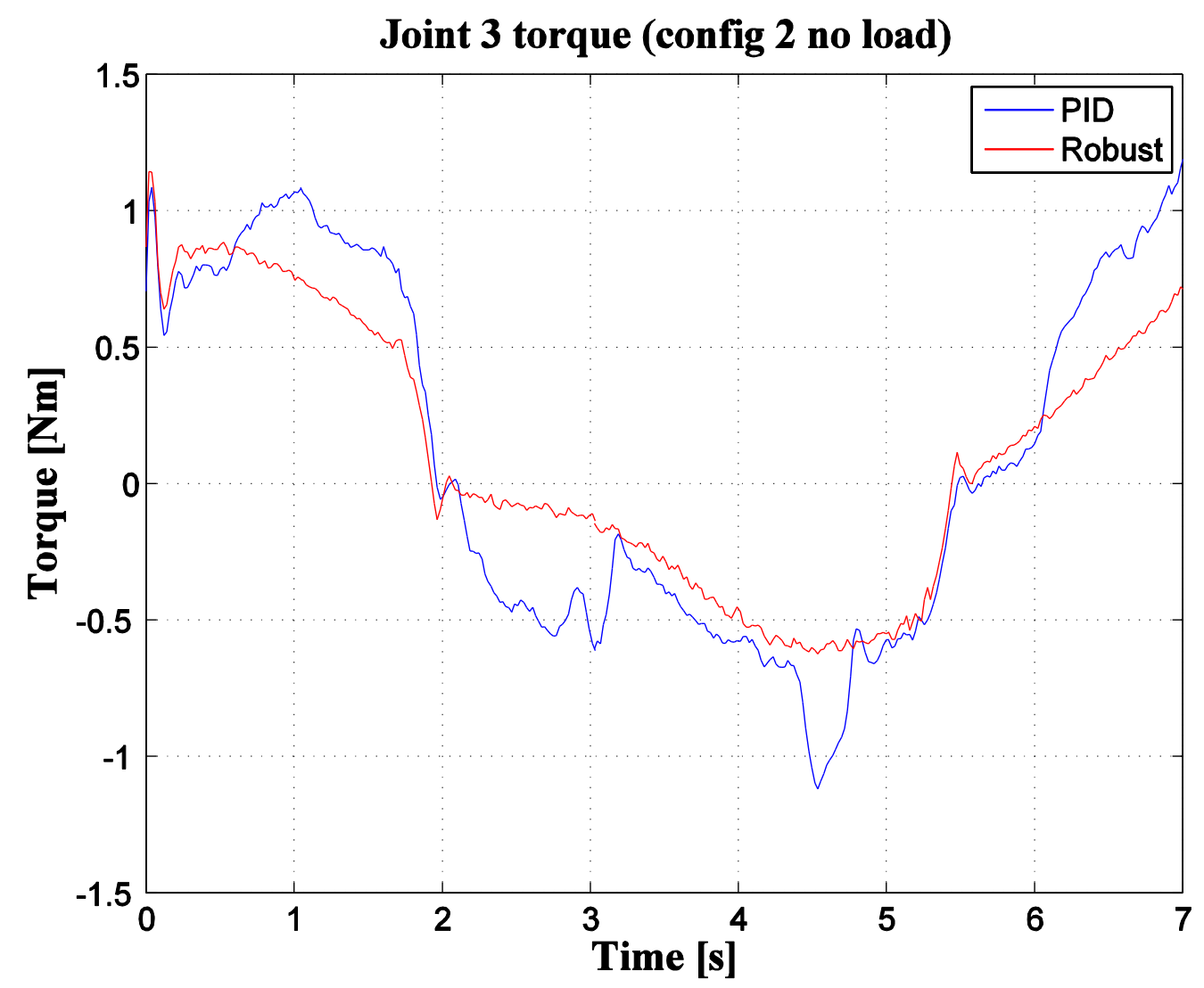

Fig. 15. joint 3 torque (config 2 no load) 


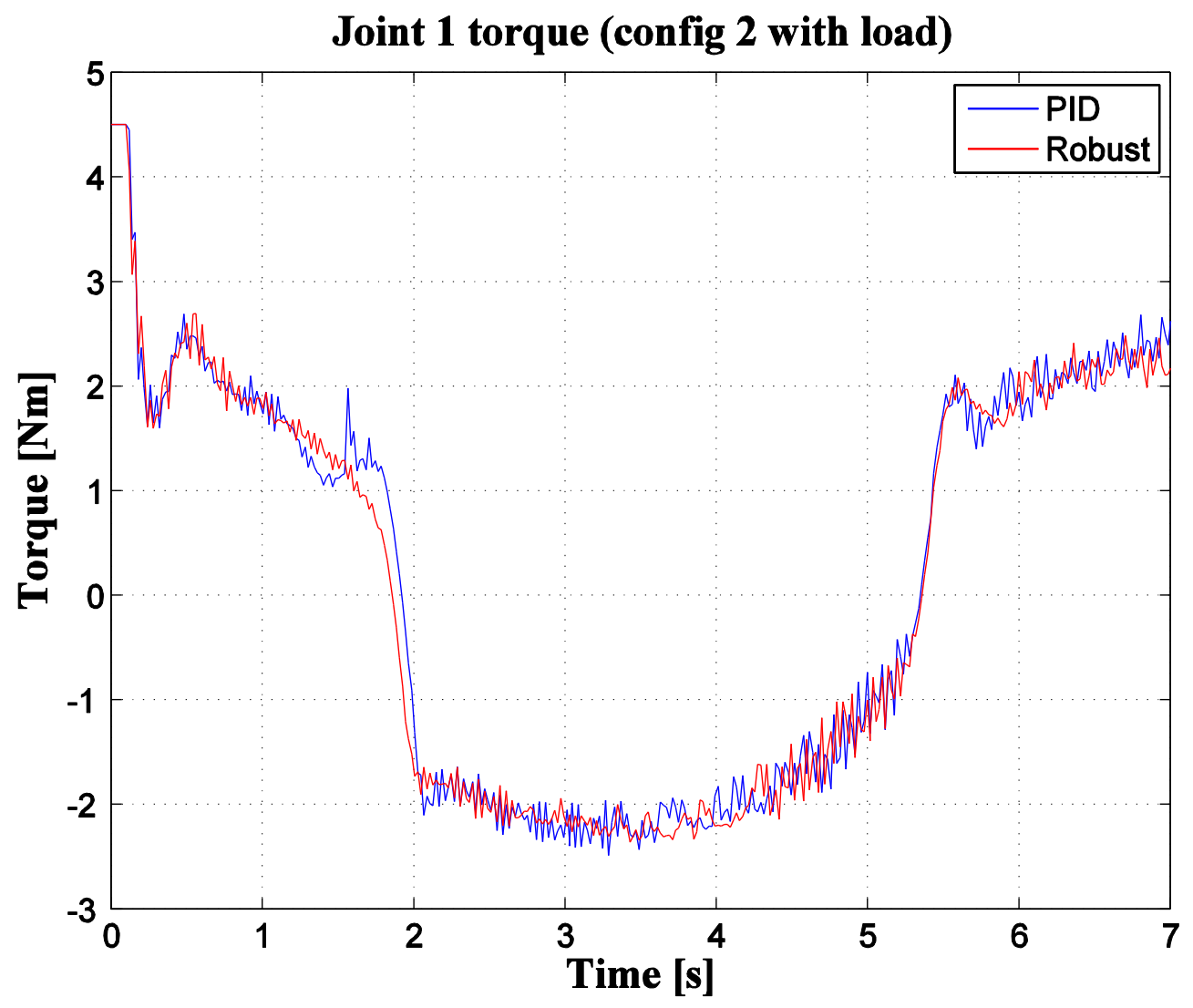

Fig. 16. joint 1 torque (config 2 with load) 


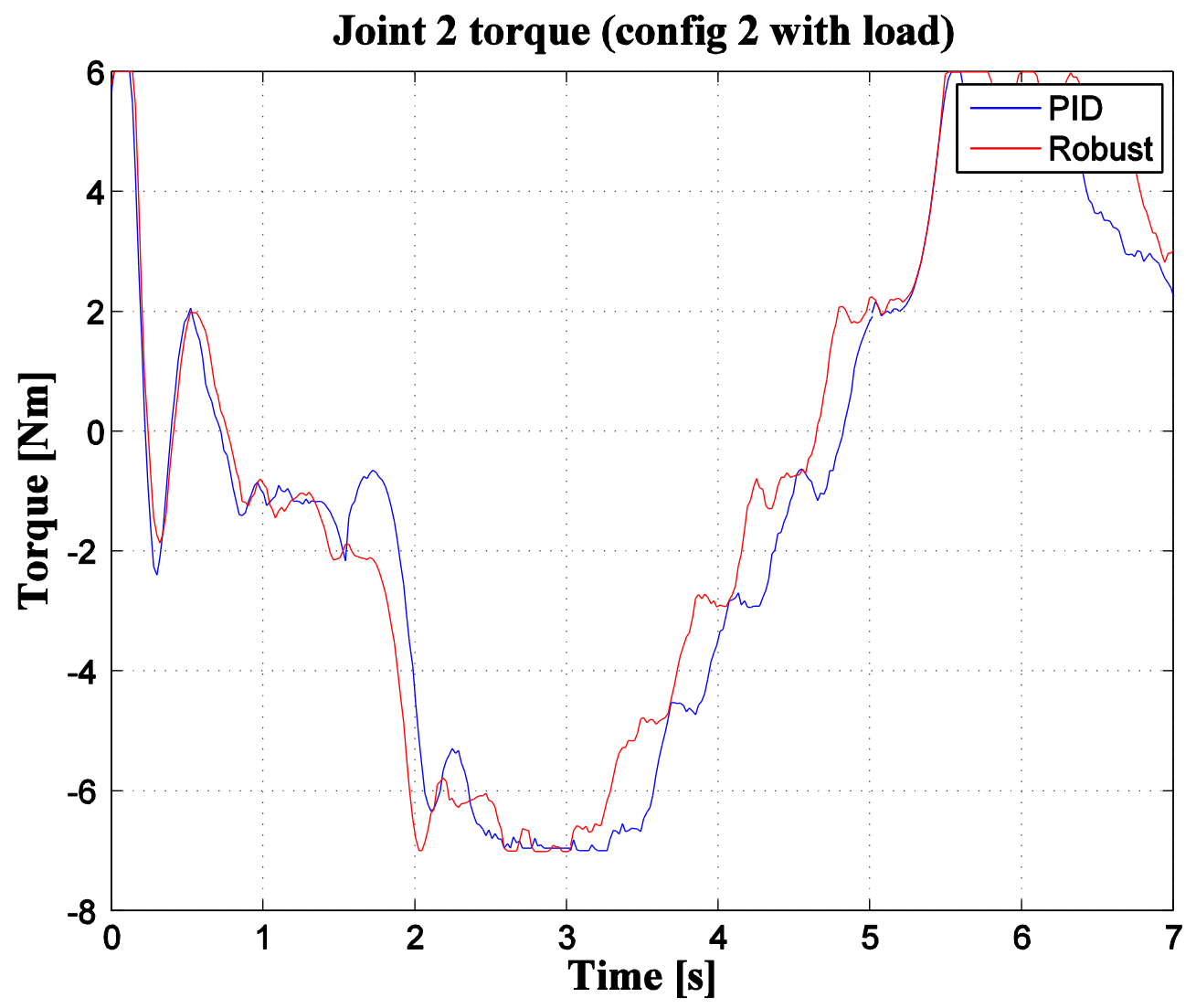

Fig. 17. joint 2 torque (config 2 with load) 


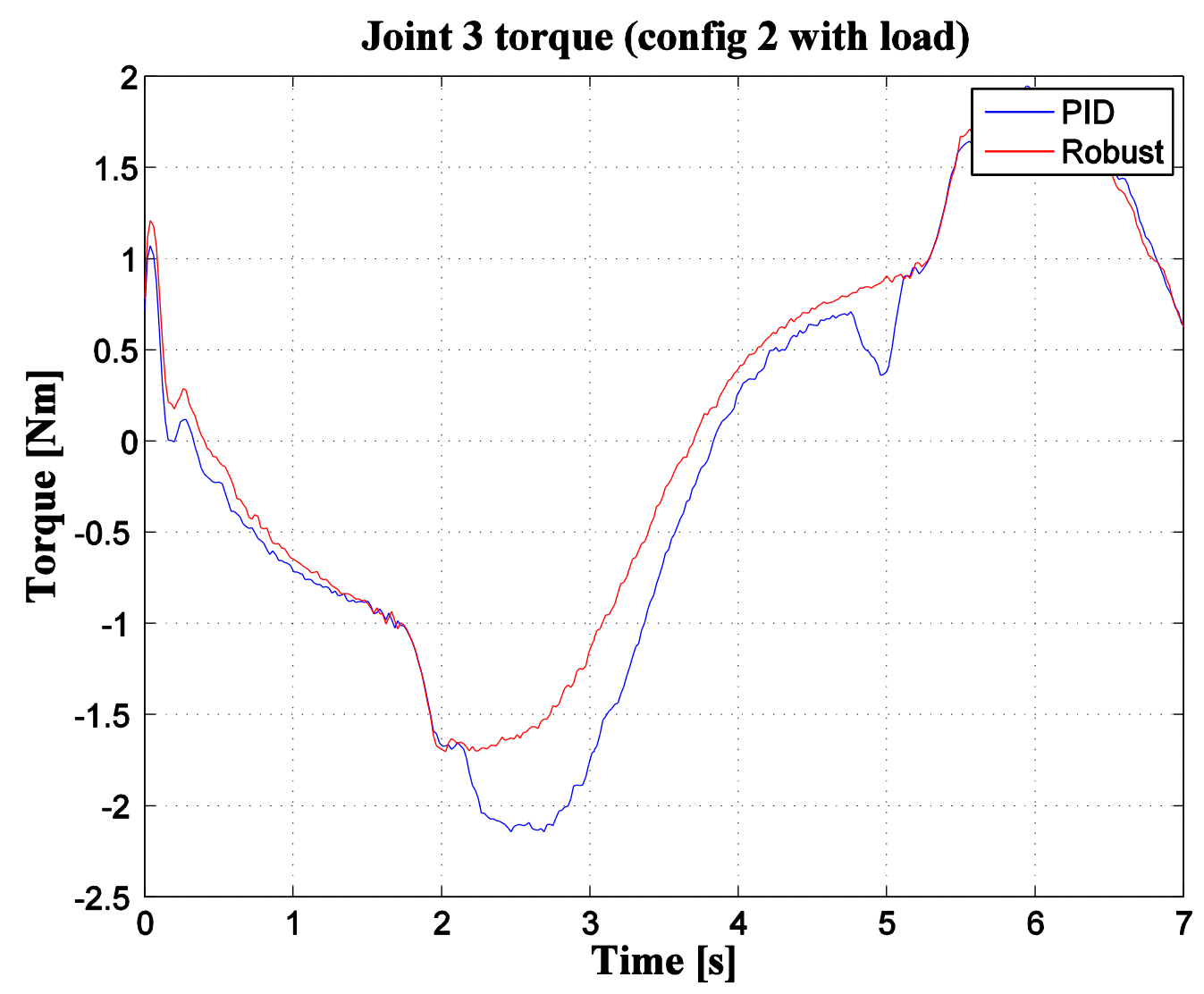

Fig. 18. joint 3 torque (config 2 with load) 


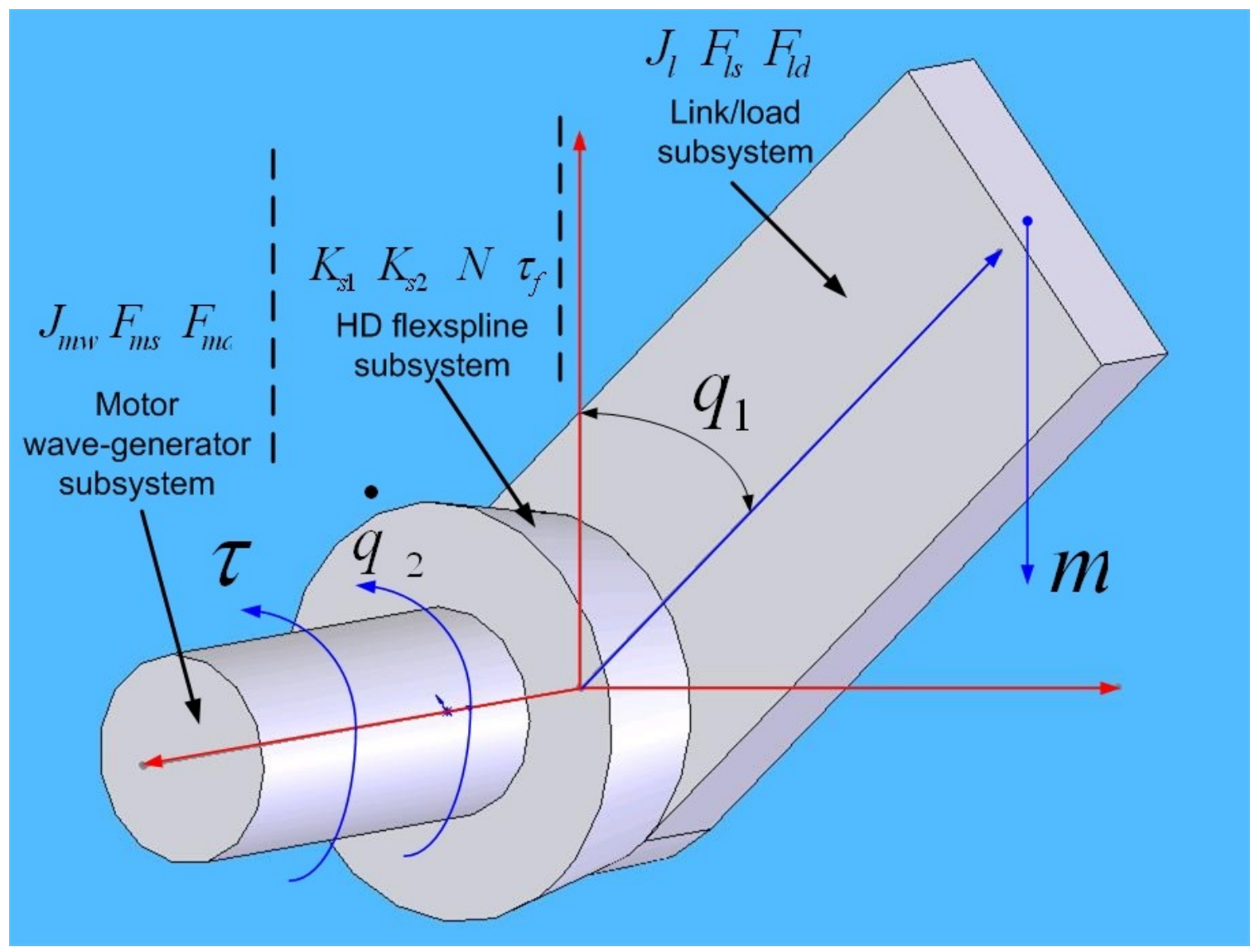

Fig. 19. Joint model

\section{References}

[1] I-M. Chen and G. Yang,"Configuration independent kinematics for modular robots". IEEE Int. Conf. Robotics and Automation,Minneapolis, MN, 1440-1445, 1996.

[2] D. Schmitz, P. Khosla and T. Kanade, "The CMU reconfigurable modular manipulator system". Carnegie Mellon Univ., CMU-RI-TR-88-7, 1998.

[3] S. Murata, H. Kurokawa, E. Yoshida, K. Tomita and S. Kokaji, "A 3-D selfreconfigurable structure". Proceeding of the IEEE International Conference on Robotics \& Automation, p432-439, 1998.

[4] M. Yim, D. G. Duff and K. D. Roufas, "Polybot: a modular reconfigurable robot". Proceeding of the IEEE International Conference on Robotics \& Automation, p514$520,2000$.

[5] I.-M. Chen, "Theory and applications of modular reconfigurable robotic system". Ph.D thesis, California Institute of Technology, CA, 1994.

[6] N. A. Aspragathos, "Reconfigurable robots towards the manufacturing of the future". Virtual conference in Reconfigurable Manufacturing Systems, IPROM, 2005

[7] G. Hirzinger, A. Albu-Schaffer, M. Hahnle, I. Schaefer, N. Sporer, "On a new generation of torque controlled light-weight robots". Proceedings of IEEE int. Conf. on Robotics and Automation, Seoul, Korea, 3356-3363, 2001. 
[8] H. Seraji, "Adaptive independent joint control of manipulators: theory and experiment". Proceeding of IEEE international conference on Robotics and Automation, vol.2, p854-61, 1998.

[9] Y. Tang, M. Tomizuka, G. Guerrero, and G. Montemayor, "Decentralized robust control of mechanical systems". IEEE Trans. Automat. Contr., vol. 26, pp. 11391144, 1981.

[10] M. Erlic and W. S. Lu, "A reduced-order adaptive velocity observer for manipulator control". IEEE Trans. Robotics and Automation, vol 11, NO. 2, 1995.

[11] T. C. S. Hsia, A. Lasky, and Zhengyu Guo, "Robust independent joint controller design for industrial robot manipulators". IEEE Trans. On Industrial Electronics, vol. 38, NO. 1, 1991.

[12] D. Luca, R. Farina, P. Lucibello, "On the control of robots with visco-elastic joints". Proceeding of IEEE International Conference on Robotics and Automation, Barcelona, Spain, 2005.

[13] A. Rodrguez. Angeles and H. Nijmeijer, "Synchronizing tracking control for flexible joint robots via estimated state feedback". Transactions of the ASME, vol. 126, pp. 162-172, 2004.

[14] H. D. Taghirad and M. A. Khosravi, "Stability analysis and robust composite controller synthesis for flexible joint robots". Advanced Robotics, vol. 20, NO. 2, pp. 181-211, 2006.

[15] D. M. Dawson, Z. Qu, M. Bridges, and J. Carroll, "Robust tracking of rigid-link flexible-joint electrically-driven robots". Proceedings of IEEE conference on Decision and Control, Brighton, England, pp. 1409-1412, 1991.

[16] V. Etxebarria, A. Sanz and I. Lizarraga, "Control of a lightweight flexible robotic arm using sliding modes". International Journal of Advanced robotic Systems, vol. 2, pp. 103-110, 2005.

[17] M. W. Spong, "Modeling and control of elastic joint robots". Journal of Dynamic Systems, Measurements, and Control, vol. 109, pp. 310-319, 1987.

[18] H. D. Taghirad and S. Ozgoli, "Robust controller with a supervisor implemented on a flexible joint robot". Proceeding of IEEE Conference on Control Applications, pp. 1188-1193, 2005.

[19] H. G. Sage, M. F. DE Mathelin and E. Ostertag, "Robust control of robot manipulators: a survey". International Journal of Control,72 (16), 1498-1522, 1999.

[20] Z. Qu and D. M. Dawson, Robust tracking control of robot manipulators. NJ: The Institute of Electrical and Electronics Engineers, Inc., 1996, pp.120-126.

[21] F. L. Lewis, C. T. Abdallah and D. M. Dawson, Control of robot manipulators. NY: Macmillan, 1993, pp. 189-255.

[22] M. W. Spong, Seth Hutchinson and M. Vidyasagar, Robot modeling and control. NJ: John Wiley and Sons, Inc., 2006, pp. 348-357.

[23] Y. Tang, M. Tomizuka, G. Guerrero, and G. Montemayor, "Decentralized robust control of mechanical systems". IEEE Transactions on Automatic control, vol. 45, NO. 4, pp. 771-776, 2000.

[24] M. Tarokh, "Decoupled nonlinear three-term controllers for robot trajectory tracking". IEEE Transactions on Robotics and Automation, vol. 15, NO. 2, pp. 369$380,1999$. 
[25] M. M. Bridges and D. M. Dawson, "Redesign of robust controllers for rigid-link flexible-joint robotic manipulators actuated with harmonic drive gearing". IEE Proc. Control theory Appl., 142(5), 508-514, 1995.

[26] A. D Luca, B. Siciliano and L. Zollo, "PD control with on-line gravity compensation for robots with elastic joints: Theory and experiments". Automatica, 41, 1809-1819, 2005.

[27] C. J. B. Macnab, G. M. T. D'Eleuterio and M. Meng, "CMAC adaptive control of flexible-joint robots using backstepping with tuning functions". IEEE Proc. international Conference on Robotics and Automation, 2679-2686, 2004.

[28] C. J. B. Macnab, Z. Qu and R. Johnson, "Robust fuzzy control for robot manipulators". IEE Proc. Control Theory Appl., 147(2), 212-216, 2000.

[29] S. Y. Lim, D. M. Dawson, J. Hu and M. S. de Queiroz, "An adaptive link position tracking controller for rigid-link flexible-joint robots without velocity measurements". IEEE Transactions on Systems, MAN, and Cybernetics - part B: Cybernetics, 27(3), pp. 412-427, 1997.

[30] G. Casalino, A. Turetta, "A computationally distributed self-organizing algorithm for the control of manipulators in the operational space, IEEE Intl. Conf. on Robotics and Automation, vol 18, NO. 22, p4050-4055, April 2005.

[31] C. J.J. Paredis, H. G. Brown and P. K. Khosla, "A rapidly deployable manipulator system". Proceeding of IEEE International Conference on Robotics and Automation. P1434-1439, 1996.

[32] N. M. Kircanski and A. A. Goldenberg, "An experimental study of nonlinear stiffness, hysteresis, and friction effects in robot joints with harmonic drives and torque sensors". International Journal of Robotics Research, 16(2), pp. 214-239, 1997.

[33] T. D. Tuttle and W. P. Seering, "A nonlinear model of a harmonic drive gear transmission. IEEE Transaction on Robotics and Automation", 12(3), pp. 368-374, 1996.

[34] H. K. Khall, Nonlinear systems. NJ:Prentice-Hall, Inc., 2002, pp589-603.

[35] Z. Li, W. Melek, C. M. Clark, "Development and characterization of a modular and reconfigurable robot, in the $2^{\text {nd }}$ International Conference on Changeable, Agile, Reconfigurable and Virtual Production (CARV 2007), Toronto, Canada, July 22-24, 2007.

[36] T. d. Tuttle and W. Seering, "Modeling a harmonic drive gear transmission". IEEE International conference on Robotics and Automation, vol. 2, pp. 624-629, 1993.

[37] H. D. Taghirad and P. R. Belanger, Modeling and parameter identification of harmonic drive systems, Journal of Dynamic Systems, Measurements, and Control. vol.120, No.4, pp.439-444, Dec. 1998. 